\title{
Mode of action of Elasnin as biofilm-formation eradicator of Methicillin-Resistant Staphylococcus aureus
}

\section{Lexin Long ( $\square$ llongaa@connect.ust.hk)}

The Hong Kong University of Science and Technology https://orcid.org/0000-0002-6350-4287 Jordy Evan Sulaiman

The Hong Kong University of Science and Technology https://orcid.org/0000-0002-0886-8707 Yao Xiao

The Hong Kong University of Science and Technology

Aifang Cheng

The Hong Kong University of Science and Technology

\section{Ruojun WANG}

Hong Kong University of Science and Technology https://orcid.org/0000-0002-2399-7080

Jessie Malit

The Hong Kong University of Science and Technology

\section{Wai Wong}

The Hong Kong University of Science and Technology

Wenchao Liu

The Hong Kong University of Science and Technology

\section{Yongxin LI}

the Hong Kong University of Science and Technology

\section{Feng Chen}

Shenzhen University

Henry Lam

The Hong Kong University of Science and Technology

Pei-Yuan Qian

The Hong Kong University of Science and Technology

\section{Article}

Keywords: Elasnin, Biofilms, MRSA, Resistance, Infections

Posted Date: August 20th, 2021

DOl: https://doi.org/10.21203/rs.3.rs-752510/v1 
License: (c) (i) This work is licensed under a Creative Commons Attribution 4.0 International License. Read Full License 


\section{Abstract}

Biofilm is made by microbes and often offers protection by making them more tolerant, resistant, and resilient to wide-range antimicrobials. Biofilm-related infections account for more than $80 \%$ of human bacterial infections and are especially prevalent in chronic tissue and device-related infections. Owing to the great challenge in treating biofilms, novel and effective antibiofilm compounds urgently need to be identified. We herein identified elasnin as a potent biofilm-targeting compound against methicillinresistant Staphylococcus aureus (MRSA) through bioassay-guided isolation of bioactive compounds from Actinobacteria. Elasnin effectively inhibited biofilm formation and eradicated pre-formed biofilms of MRSA, and it displays low cytotoxicity with a low risk of resistance development. Transcriptomic and proteomic analyses combined with confocal microscopy observation revealed that elasnin destroyed the biofilm matrix in a time-dependent manner and interfered with cell cycle during the exponential phase, primarily by repressing the expression of virulence factors. Moreover, the biofilm cells released from elasnin treatment showed increased sensitivity to penicillin G. Overall, this study identified elasnin as a promising biofilm-eradicating compound against MRSA and shed light on its action mechanism.

\section{Introduction}

Biofilms are collections of microorganisms that grow on various surfaces. In biofilms, organized cells are embedded in a matrix containing diverse self-produced extracellular polymeric substances (EPSs) such as polysaccharides, proteins, nucleic acids, and lipids ${ }^{1-3}$. Cells residing within the biofilms are usually more tolerant, resistant, and resilient to external threats than planktonic cells, owing to the limited penetration, altered growth rate, increased rate of horizontal gene transfer, cell differentiation, and enzymes modifications ${ }^{4-6}$. Consequently, conventional antimicrobial agents exhibit a reduced efficacy when treating biofilms-associated infections, and extremely high concentrations are required to eradicate the pre-formed biofilms ${ }^{4,7,8}$.

Biofilm-associated infection is a major problem in clinics and the healthcare industries, accounting for about $80 \%$ of human bacterial infections and $65 \%$ of nosocomial infections $s^{6,9-11}$. Biofilm formation is crucial for bacterial pathogenesis that results in higher morbidity and mortality and is the leading cause

of chronic and device-related infections ${ }^{12-14}$. Staphylococci are commonly found on human skin and the most frequently reported source of biofilm-related infections. Among cases of infections, one of the most dangerous pathogens in clinics to date is Staphylococcus aureus, whose resistance is frequently reported to be related to biofilm formation ${ }^{15,16}$. The typical process of staphylococcal biofilm formation consists of three main stages, namely attachment, proliferation/maturation, and detachment, during which a large array of $S$. aureus virulence factors and secreted substances are involved ${ }^{17-19}$. They include adhesive surface proteins, proteases, proteolytic enzymes, EPSs, toxins, and many others. For instance, autolysin (Atl), wall teichoic acids (WTAs), and adhesive surface proteins like fibronectin-binding proteins (FnBPA and $\mathrm{FnBPB}$ ) and clumping factors (ClfA and $\mathrm{ClfB}$ ) are involved in the attachment stage, facilitating adhesion and colonisation of bacteria ${ }^{20-22}$. In the second stage, main matrix components like 
extracellular DNA (eDNA), polysaccharide intracellular adhesin (PIA), and other adhesive proteins are largely secreted, which assist biofilm maturation and rapid cell proliferation ${ }^{17,23}$. To shape the biofilm structure, degradative enzymes such as nucleases and proteases are secreted. This enzymatic degradation is believed to cause biofilm detachment, which then facilitates the systemic dissemination of bacterial infection ${ }^{17,19}$.

Biofilm formation is tightly controlled by the coordination of multiple signaling pathways, in which the quorum-sensing system Agr and the global regulators SarA protein family play the central roles ${ }^{17,24,25}$. The Agr system encodes two different transcripts, RNAll and RNAlll. RNAll encodes for the traditional twocomponent transduction system, and the RNAll functions as an intracellular effector that directly or indirectly controls the expression of numerous virulence factors (e.g., proteases and surface adhesins) involved in biofilm formation, and cell wall hydrolases with roles in cell cycle and pathogenesis ${ }^{26-31}$. The SarA protein contains many members such as SarZ, SarX, and SarR, most of which have been shown to control the expression of virulence factors. Among all proteins in this family, SarA is the most extensively studied. SarA is a global regulator that positively controls its own expression, PIA synthesis, agr system, adhesins and toxins; it also strongly represses the production of proteases ${ }^{17,32-35}$. Notably, many studies have revealed the interconnected roles of sarA and agr in the switching between the formation and detachment of $S$. aureus biofilm. The upregulation of adhesins, PIA, and protease inhibitors by sarA induces early biofilm adherence, and the activation of peptides and nucleases by agrassist biofilm dispersion ${ }^{36-39}$. Biofilm infections have now become a great threat to human health. However, for the past decades, drug discovery has primarily focused on treating planktonic cells. Consequently, the drugs that could be used for biofilm-associated infections are very limited. Owning to the increased gene transfer and differentiation within biofilms, cells that are exposed to subinhibitory concentrations of drug (caused by limited penetration) have a higher propensity to develop antibiotic resistance ${ }^{40-42}$. Recently, many efforts have been exerted towards the discovery of new antibiofilm agents, such as those that target the EPS by inhibiting EPS production, binding to EPS adhesins, or degrading the EPSs (dispersin B and DNase I). Other strategies such as inducing biofilm dispersal and metabolic interference are also potential directions for future drug discoveries and developments ${ }^{43,44}$.

Actinobacteria is one of the largest taxonomic unit in the bacterial domain and has always been a promising source of antimicrobial compounds. Among 22,000 bioactive compounds discovered by the early 2000 s, $45 \%$ of them are produced by Actinobacteria ${ }^{45}$. In the present study, through the bioassayguided isolation of bioactive compounds from Actinobacteria, we discovered that elasnin, a marine biofilm-inhibiting compound identified in our previous work ${ }^{46}$, as a potent biofilm-eradicating compound against methicillin-resistant $S$. aureus (MRSA). Elasnin can inhibit biofilm formation and effectively eradicate mature biofilms of MRSA at low concentrations. To further investigate its mode of action, we performed transcriptomic and proteomic analyses, confocal and scanning electron microscopy imaging, gene-transcription inhibition and complementation, and antimicrobial and antibiofilm assays. Altogether, these methods elucidated the process of elasnin-induced biofilm eradication and highlight the key genes that were affected during treatment. 


\section{Results}

\section{Bioassay-guided isolation of biofilm-targeting compounds.}

Secondary metabolites produced by 12 actinobacterial strains under different culture conditions were assessed for their minimum inhibiting concentrations (MIC), minimal biofilm inhibitory concentrations (MBIC), and minimal biofilm-eradication concentrations (MBEC) against Gram-positive bacteria (MRSA) and Gram-negative bacteria (Escherichia coli, E. coli). This was followed by bioassay-guided fractionation which led to the isolation of three antimicrobial compounds (e.g., xanthone, hitachimycin, and resistomycin) and the antibiofilm compound - elasnin, which showed potent activity against MRSA (Table 1).

Purified elasnin was then compared with vancomycin in terms of MIC, minimum bactericidal concentration (MBC), MBIC, and MBEC assays against MRSA. The MIC values reflect the antibiotics' antimicrobial activities against planktonic cells; MRSA was found to be susceptible to vancomycin (MIC of $0.625-1.25 \mu \mathrm{g} / \mathrm{mL}$ ) and elasnin (MIC of $1.25-2.5 \mu \mathrm{g} / \mathrm{mL}$ ) (Fig. 1a). Meanwhile, the MBC values measure the compounds' killing effect on cells. Vancomycin exhibited strong bactericidal activities with a fast decrease in cell density and an MBC between 20 and $50 \mu \mathrm{g} / \mathrm{mL}$, whereas elasnin showed bacteriostatic activity with an MBC exceeding $100 \mu \mathrm{g} / \mathrm{mL}$ and no significant changes in cell density (Fig. 1a and 1b). The MBIC values represent the ability of the compounds to inhibit biofilm formation, whereas MBEC values indicate the ability to eradicate pre-formed mature biofilms. Elasnin and vancomycin showed strong biofilm-inhibiting activities against MRSA with an MBIC value of $1.25-2.5$ $\mu \mathrm{g} / \mathrm{mL}$ (Fig. 1C), the pre-formed biofilms showed strong resistance to vancomycin with $\mathrm{MBEC}_{50}$ of $10-20$ $\mu \mathrm{g} / \mathrm{mL}$. However, they can still be eradicated with elasnin at low concentrations ( $\mathrm{MBEC}_{50}$ between 0.625 $1.25 \mu \mathrm{g} / \mathrm{mL}$ ) (Fig. 1d). Overall, elasnin exhibited higher effectiveness in biofilm inhibition and especially in biofilm eradication, relative to its activities against planktonic cells. Cells can also still proliferate after stopping exposure to elasnin, suggesting that elasnin could be used as a biofilm-targeting compound that interfered with the process of biofilm formation and maintenance rather than killing planktonic cells.

To explore the mode of action of elasnin, we initially attempted to identify MRSA mutants that were resistant to elasnin. Interestingly, the MIC of MRSA towards elasnin did not change during continuous serial passaging in the presence of subinhibitory concentrations of elasnin for over 45 days (Fig. 1e). This finding suggested that resistance was not developed during this period. Elasnin's cytotoxicity was also assessed using sensitive neuronal cell lines HT22 and Neuro2a, and no cytotoxicity was observed for both cell lines when treated with $10 \mu \mathrm{g} / \mathrm{mL}$ elasnin (Fig. S1a). The absence of cytotoxicity in HT22 cells was observed for elasnin concentration up to $25 \mu \mathrm{g} / \mathrm{mL}$ (10 times of $\mathrm{MBIC}_{90}$ and $\mathrm{MBEC}_{50}$ ), but the cell viability was reduced for higher concentrations $(>25 \mu \mathrm{g} / \mathrm{mL})$ (Fig. S1b).

\section{Elasnin destroyed the biofilm matrix}


Confocal laser scanning microscopy (CLSM) on stained biofilm cells and biofilm matrix was performed to examine the effect of elasnin on biofilm structures. Biofilm-inhibition assay showed that untreated biofilms had distinct shapes with a high density of organised cells and matrix (Fig. 2a), whereas the elasnin-treated biofilms exhibited a large decrease in the density of cells and matrix, and both were randomly distributed (Fig. 2b). Biofilm-eradication assay revealed that pre-formed biofilms were dispersed after elasnin treatment, and most biofilm cells were released into the medium (Fig. $\mathbf{2 d}$ ). Confocal images demonstrated that the distribution patterns of the cells changed after elasnin treatment, i.e., untreated biofilm cells were distributed as clumps with rough edges (Fig. 2c), whereas elasnin-treated biofilm cells were distributed as narrow strips with smooth edges (Fig. 2d). Similarly, the high density of organised biofilm matrix became sparse and scattered after elasnin treatment. According to quantitative analysis, the biofilm cells and matrix were significantly reduced after treatment. Compared with untreated biofilms, elasnin-treated ones exhibited $\sim 80 \%$ and $35 \%$ decrease in the density of cells and matrix for biofilminhibition assay, respectively (Fig. $\mathbf{2 e}$ ). For biofilm-eradication assay, the reduction in cells and matrix densities were over $50 \%$ and $70 \%$, respectively (Fig. 2f).

\section{Gene expression of virulence factors and products in the extracellular region were downregulated following elasnin treatment.}

Out of 2791 detected gene transcripts, 1010 were differentially expressed ( $\geq 2.0$-fold change in gene expression) on MRSA biofilm cells treated with elasnin for $6 \mathrm{~h}$, compared with untreated biofilm cells (control) after $6 \mathrm{~h}$ of treatment. The percentage of eradicated cells after $6 \mathrm{~h}$ of treatment is shown in Fig. S2a). The number of differentially expressed genes (DEGs) decreased to 668 when the treatment time was extended to $12 \mathrm{~h}$. For cells released from the biofilms, 720 and 609 genes were differentially expressed between the treatment and control groups at 6 and $12 \mathrm{~h}$, respectively (Fig. 3a). Further analysis of the RNA-seq results by principal-component analysis (PCA) exhibited clear separation between clusters of elasnin-treated and untreated samples along the PC1 axis, indicating that the differences of gene expression were primarily contributed by elasnin treatment (Fig. $\mathbf{3 b}$ ).

DEGs were then processed by gene ontology (GO) enrichment analysis in terms of their molecular function, cellular component, and biological process (Fig. 3c). For the 6 h-treated samples, amongst the enriched GO terms of downregulated genes, the cellular component of the extracellular region was observed only for biofilm samples, whereas the biological process of pathogenesis was shown only in released cells samples. Additionally, $\mathrm{GO}$ terms of translation, transmembrane transport, and integral component of the membrane were observed to be downregulated in biofilm and released cells. For $12 \mathrm{~h}-$ treated samples, downregulated genes were enriched in the GO term of extracellular region and pathogenesis for biofilm and released cells, whereas membrane components were observed only for released cells.

DEGs were also analysed using the Kyoto Encyclopedia of Genes and Genomes (KEGG) pathway assessment and the gene expression in selected pathways are shown in the heatmap in Fig. 4a. After 
elasnin treatment, overexpressed genes were dominant in the annotated KEGG categories of signal transduction (two-component system and HIF-1 signalling pathway), whereas the majority of the downregulated genes were annotated to membrane transport ( $A B C$ transporters, phosphotransferase system, and bacterial secretion system), quorum sensing, and especially staphylococcus infection and beta-lactam resistance. Results of hierarchical clustering of gene-expression data (Fig. $\mathbf{4 b}$ ) revealed that biofilm cells exhibited the most unique gene-expression pattern after $6 \mathrm{~h}$ of elasnin treatment. Therefore, the $6 \mathrm{~h}$ - treated biofilm samples were subsequently used to build the gene-interaction network (Fig. 4c). As shown in the network, elasnin-treated biofilm cells exhibited a lower expression level of the genes involved in pathogenesis, such as global regulon (sarA and RNAllI), EPS production (icaA, icaB, and icaC), murein hydrolases and autolysins (att, lytR and $\operatorname{cidA}$ ), serine protease ( $s s p A, s s p B, s s p C, \operatorname{ssp} P$, and $s p / B)$, toxin ( $h / d, h / g C$ and $h / y$ ), and adhesins ( $f n b A, c / f B, s d r D$, and emp). Interestingly, genes related to cell-wall organisation and cell division (for example, murB, murC, murD, mraY, diviB and ftsZ) turned out to be upregulated following elasnin treatment.

\section{Elasnin interfered with the cell cycle and EPS production of MRSA and reduced cell resistance to penicillin G}

To further investigate the mode of action of elasnin in growth inhibition and biofilm eradication of MRSA, label-free quantitative proteomics analysis was used to study the protein expression dynamics of MRSA biofilm cells during biofilm eradication upon elasnin treatment (Fig. 5a). Analysis revealed that 105 proteins were differentially expressed in the MRSA biofilm cells treated with elasnin for $2 \mathrm{~h}$ (compared with untreated samples). Downregulation and repression were observed for proteins involved in DNA repair and replication, cell division, and cell-wall organisation, pathogenesis (such as the virulence regulator SarX and SaeR), and secreted virulence factors (EsXA). Moreover, amidohydrolase (AID39263.1) and secreted lipase and dipeptidyl-peptidase (AID41306.1) were upregulated. After $6 \mathrm{~h}$ of treatment, the number of differentially expressed proteins (DEPs) reached 250, which was the highest among all time points ( 2 and $12 \mathrm{~h}$ ). At $6 \mathrm{~h}$, we observed that elasnin downregulated or repressed numerous proteins involved in DNA repair and replication, cell division and cell-wall organisation as well as in the production of virulence factors (like adhesin SdrD, toxin $\mathrm{HlgB}$ and $\mathrm{HlgC}$, and autolysin LytM). Furthermore, the expression of secreted peptidase (Staphylococcal superantigen-like 1 (Ssl1)) and amidase (AID41356.1) increased. When prolonged treatment duration to $12 \mathrm{~h}$, the number of DEPs decreased to 154 , and most DEPs were primarily related to translation and pathogenesis, with a few involved in cell division and cellwall organisation. Except for LytM and lipase, no other hydrolases, lyases, and proteins involved in DNA replication and repair were differentially expressed at this time point.

We focused on the changes in the expression level of several hydrolases and proteins related to cell division (SepF) and cell-wall organisation (IsaA, Ssl1, LytM, Atl, MurT, MurF, MurD, and MurB) (Fig. 5b). As revealed by the changes in control samples, the abundance of hydrolases encoded by IsaA, LytM, and Atl should reach the highest at $6 \mathrm{~h}$, and the abundance of staphylococcal superantigen-like 1 should be 
reduced during the eradication. However, results showed that elasnin treatment reduced the abundance of IsaA and LytM, repressed the expression of autolysin (AtI), and stopped the changes in Ssl1. In the control samples, the abundance of SepF exhibited a continued increase from $2 \mathrm{~h}$ to $12 \mathrm{~h}$, whereas the abundance of proteins involved in cell-wall biogenesis (Mur family proteins) remained stable with little reduction (0.8fold change) of proteins encoded by murB. An obvious reduction of abundance occurred in Mur family proteins after 6-h elasnin treatment, whereas the expression of SepF was repressed by elasnin throughout the entire process.

The impact of elasnin treatment on biofilm-matrix composition was visualised using CLSM with EPS histochemical staining. As shown in Fig. 5c, the amount of polysaccharides and eDNA in the biofilm matrix was significantly reduced after elasnin treatment. Cells released from the biofilms were collected for MIC and MBC assay using a beta-lactam antibiotic, penicillin G. Consistent with the transcriptomicanalysis results, released cells induced by elasnin exhibited lower resistance to penicillin $\mathrm{G}$ with about five times reduction in the MIC $(0.8-4 \mu \mathrm{g} / \mathrm{mL})$ and $\mathrm{MBC}(4-20 \mu \mathrm{g} / \mathrm{mL})$ compared with the MIC (4-20 $\mu \mathrm{g} / \mathrm{mL})$ and $\mathrm{MBC}(>100 \mu \mathrm{g} / \mathrm{mL})$ of naturally released cells (CR) (Fig. $\mathbf{5 d}$ ).

\section{Elasnin caused cell-wall defect in MRSA cells, and sarZ may play a key role in elasnin-induced biofilm eradication}

Transcriptomics and proteomics analysis revealed that combined with greater sensitivity of elasnintreated cells towards penicillin G, elasnin may also interfere with the proper cell division and cell-wall organisation process during the exponential phase when numerous cells are undergoing cell division (Fig. 6). Therefore, scanning electron microscopy (SEM) was used to observe the morphological changes in MRSA cells after $6 \mathrm{~h}$ of exposure (Fig. 7a). Consistent with our hypothesis, untreated biofilms showed a dense layer of the normal grape-like cell clusters, whereas elasnin-treated biofilms were scattered cells, the majority of which exhibited a defective appearance with clear collapses around the center of the cell. Interestingly, defective cells were also observed in the untreated biofilms, but they accounted only for less than $1 \%$ ( 2 of $~ 200$ ) of the total cells, whereas the proportion of defective cells was more than $70 \%$ ( 25 of $34)$ in elasnin-treated biofilm.

Given the complex regulatory network of virulence factors, we sought to find out the main determinant by comparing the biofilm-eradication activity of transcription-inhibited mutants and complemented strains. Regulators (rot and sarX) were induced following elasnin treatment were transcriptionally inhibited by CRISPR/Cas 9 transcription inhibition system pCasiSA, whereas downregulated genes (sarA, sarZ, sarR, and RNAIII) were complemented with the expression vector pRMC2 (shown by the RT-qPCR in Fig. S3). MBEC and biofilm-eradication efficacy $(5.0 \mu \mathrm{g} / \mathrm{mL})$ were determined using the MRSA mutants (Fig. 7b). Compared with the control strains (strains with empty plasmids), mutants of sarA, sarR, and RNAIll showed increased MBECs of $1.25-2.5 \mu \mathrm{g} / \mathrm{mL}$, and the complemented mutant strains exhibited reduced eradication rates from $50.08 \%$ to $77.75 \%$. No increase in $\mathrm{MBEC}_{50}$ was observed in mutants of rot and 
sarX, but the eradication efficiency $(5 \mu \mathrm{g} / \mathrm{mL})$ of elasnin reduced to $69.40 \%$ and $59.61 \%$ respectively. Among all of the mutants, the sarZ-complemented mutant showed the highest resistance to elasnin with an MBEC above $10 \mu \mathrm{g} / \mathrm{mL}$ and an eradication rate of almost $0 \%$. Similarly, the ability of elasnin to inhibit biofilm formation of the sarZ-complemented mutant was also largely reduced with an $\mathrm{MBIC}_{90}$ above 10 $\mu \mathrm{g} / \mathrm{mL}$ (Table. S1). All the mutants showed resistance to elasnin in biofilm-formation inhibition assay with $\mathrm{MBIC}_{90}$ of $5-10 \mu \mathrm{g} / \mathrm{mL}$ for mutants of $\operatorname{sar}$, rot, $\operatorname{sar} X$, and $\mathrm{MBIC}_{90}$ higher than $10 \mu \mathrm{g} / \mathrm{mL}$ in mutants of sarR and RNAIll. Interestingly, mutants of sarR, RNAll, and especially sarZ that developed the highest resistance to elasnin treatment, showed a significant reduction in the biofilm formation compared with strains having an empty plasmid and the wild-type strain. Overall, these results suggested that the impact of elasnin on virulence regulons affected biofilm formation, and that the repression of sarZ was primarily responsible for the biofilm eradication (Fig. 7c).

\section{Discussion}

The selective pressure exerted by antimicrobials enriches the naturally existing antibiotic-resistant bacteria in the environment, thereby accelerating the establishment of resistance in a population ${ }^{47-49}$. With the protection provided by the biofilm matrix and the intense gene transfer and differentiation within it, compounds that simply kill cells but leave the biofilm matrix intact for microbial utilisation are more likely to boost resistance development. Facing the inevitable rise in antibiotic resistance and the considerable challenges in biofilm-associated antimicrobial therapy, effective antibiofilm agents, particularly those that can effectively eradicate established biofilms are urgently needed. In this work, we conducted bioassay-guided compound isolation to identify the biofilm-targeting compounds that can effectively inhibit and eradicate the biofilms without killing the cells. Elasnin was identified as a promising biofilm-eradicating drug candidate against MRSA. It eradicated biofilms by destroying the biofilm matrix and did not exert a considerable effect on the viability of the released cells, thereby delaying the development of resistance. The low risk of resistance development following elasnin treatment was further confirmed through the non-observable increase in MIC upon subjecting MRSA cells to continuous serial passaging in the presence of subinhibitory concentrations of elasnin. The cells released following elasnin treatment were also more susceptible to the beta-lactam antibiotic penicillin $\mathrm{G}$. Elasnin further exhibited low cytotoxicity towards different cell lines, consistent with a previous study ${ }^{50}$.

The interesting mechanism of elasnin in eradicating established MRSA biofilm (Fig. 6) was then elucidated by a series of analyses. As a part of pathogenesis, the formation and maintenance of biofilm require the participation of numerous virulence factors, as well as the cell cycle, and cell-wall hydrolases (LytM and autolysin) that are required for cell separation, which are also regulated by the virulence regulon. Therefore, large numbers of proteases and cell-wall hydrolases are expressed during the exponential phase when biofilms undergo proliferation and maturation. However, owning to elasnin's repression of the virulence factors' expression, the production of some cell-wall hydrolases, adhesins, and EPSs were inhibited. Consequently, cells cannot properly divide and very limited EPSs were synthesized. Meanwhile, some lipase and proteases were largely secreted, causing the degradation of the existing 
EPSs and the destruction of the biofilm matrix. Consequently, the cells were released back to the media. Amongst the released cells, most had a defective structure caused by the inhibited cell division and the downregulation of genes encoding the integral component of the membrane. Thus, cells released from the elasnin-treated biofilms showed increased susceptibility to the beta-lactam antibiotic penicillin $\mathrm{G}$. This finding indicated the potential application of elasnin as a combinatorial therapy and the possibility of rescuing old drugs that had become ineffective owning to resistance.

S. aureus has a very complex regulatory network of biofilm formation and virulence expression ${ }^{51-57}$, in which many of the important regulators were affected by elasnin. Accordingly, multiple mutants were generated to reveal the key determinants. By comparing the bioactivities of the mutants, we found that all mutants showed increased ability in resisting the inhibition of biofilm formation caused by elasnin, but elasnin lost its efficacy only in eradicating the established biofilm of mutants complemented with sarz. The complementation of sarA can increase the production of EPSs and adhesins assisting the biofilm maturation, whereas the complementation of sarR and RNAlll and the repression of sarX can increase the production of proteases and cell-wall hydrolases enabling the cell division ${ }^{29,30,54}$. Consequently, these mutants exhibited increased resistance towards the inhibition of biofilm formation caused by elasnin, and mutants with increased production of proteases and hydrolases showed reduced ability to form biofilms (Fig. 7c and Table S1). Previous studies have reported that sarZ activates the expression of RNAIII, represses SarA, and regulates the production of proteases independently ${ }^{56,58}$. Indeed, complementation of sarZ caused a reduction in the biofilm formation (Table S1) and restored the cell's ability to divide, perhaps by repressing sarA and increasing the production of proteases and cell-wall hydrolases through RNAll or independent from of it. However, stopping biofilm eradication (as seen in the sarZ-complemented mutant, Fig. 7b) requires the inhibition of matrix destruction caused by the increase in degrading exoproteins, and no studies have reported the role of sarZ in this process. Accordingly, (i) sarZ may be a repressor of the production of the degrading exoproteins, or (ii) the proteases upregulated by sarZ inactivate the corresponding exoproteins, and this regulatory pathway was independent of the regulons listed above. Exhaustive efforts have been exerted in studies on biofilm formation/dispersion and its regulation, but gaping holes remain to be filled. During the elasnin-induced eradication, many uncharacterised hydrolases and lyases were highly expressed, a phenomenon believed to be related to the regulation of sarZ and indicating that more determinants and signaling pathways were involved in the switch between the attachment and detachment of biofilm. Additionally, the roles of elasnin in intra- and intercell communications were also worth exploring in the future, especially because elasnin is produced by multiple Streptomyces species and has a similar structure to photopyrones, the novel quorum-sensing signals in Photorhabdus ${ }^{59}$.

In the present study, through bioassay-guided compound isolation, we identified elasnin as a biofilmeradicating compound. Elasnin destroyed the biofilm matrix, had low toxicity, and a low risk of resistance development in MRSA cells. Further mechanism study revealed that elasnin repressed the expression of several virulence regulators, resulting in the inhibition of cell division and the degradation of biofilm matrix (primarily during the exponential phase), and sarZ was the key determinant of this process. 
Furthermore, cells released from the elasnin-treated biofilms were more sensitive to penicillin $\mathrm{G}$ owning to the large proportion of defective cells. In summary, we discovered elasnin as an effective anti-virulence and biofilm-eradicating compound harboring great potential in treating biofilm-associated infections and elucidated its mode of action in MRSA biofilms.

\section{Materials And Methods}

\section{Strains, media, and chemicals}

Twelve actinobacterial strains (Table 1) were purchased from the German Collection of Microorganisms and Cell Cultures (DSMZ, Braunschweig, Germany). The MRSA ATCC 43300 and E. coli ATCC 25922 were purchased from American Type Culture Collection. Soybean powder was purchased from Wugumf, Shenzhen, China. Soluble starch was purchased from Affymetrix, Santa Clara, CA, USA. Magnesium sulfate hydrate was purchased from Riedel-de-Haën, Seelze, Germany. Bacteriological peptone and tryptone soya broth (TSB) were obtained from Oxoid, Milan, Italy. Mueller-Hinton broth (MHB) was purchased from Fluka Chemie AG, Buchs, Switzerland. Phosphate-buffered saline (PBS) was purchased from Thermo Fisher Scientific Inc., San Jose, CA, USA. Lysogeny broth (LB), glucose, 3-(4,5dimethylthiazol-2-yl)-2,5-diphenyltetrazolium bromide (MTT), and 1-butanol were purchased from VWR International Ltd, Leicestershire, UK. Antibiotics, stains, and all other chemicals were supplied by SigmaAldrich Corporation, Saint Louis, MO,USA.

\section{Compound isolation and purification}

Elasnin and natural products from 12 Actinobacteria strains were isolated and purified as previously described $^{46}$. In a typical procedure, stock cultures were inoculated into $50 \mathrm{~mL}$ of AM4, AM5, and AM6 media (Table S2) containing glass beads and incubated at $22^{\circ} \mathrm{C}$ and $30^{\circ} \mathrm{C}$ on a rotary shaker $(170 \mathrm{rpm})$ for 3, 5, and 7 days. The crude extracts were extracted with 1-butanol and dissolved in DMSO for storage and bioassay. Pure compounds were isolated by reversed-phase high-performance liquid chromatography (HPLC) (Waters 2695, Milford, MA, USA) using a semi-prep C18 column (10×250mm). Elasnin was extracted from the secondary metabolites produced by Streptomyces mobaraensis DSM 40847 after 5 days of incubation in the AM4 medium at $30^{\circ} \mathrm{C}$ and purified with HPLC.

\section{Antibacterial assay}

MICs and MBCs were determined with MRSA ATCC 43300 and E. coli ATCC 25922, according to the Clinical and Laboratory Standards Institute guideline CLSI M100 (2018). In a typical procedure, a $10^{5}$ $\mathrm{CFU} / \mathrm{mL}$ overnight culture of test strains was inoculated into MHB and treated with testing compounds at a series of concentrations. After incubation for $24 \mathrm{~h}$, the minimum concentrations at which no bacterial growth was visible were recorded as the MICs. MBCs were measured following the MIC assay by plating 1 $\mathrm{mL}$ of suitably diluted culture broth from each well on Mueller-Hinton agar (MHA) plate. MBC was defined as the lowest concentration at which an antimicrobial agent caused $>99.9 \%$ reduction in cells. Each assay was performed in duplicate and repeated three times. 
MRSA ATCC 43300 was used for the concentration-response curve study. A culture of $4 \times 10^{5} \mathrm{CFU} / \mathrm{mL}$ MRSA in the exponential phase was inoculated into MHB with various concentrations of elasnin and vancomycin in $15 \mathrm{~mL}$ falcon tubes. Tubes were incubated at $37^{\circ} \mathrm{C}$ on a rotary shaker for $24 \mathrm{~h}$. Then $1 \mathrm{~mL}$ of culture broth in each tube was diluted with $\mathrm{MHB}$, and $1 \mathrm{~mL}$ of diluted bacteria was plated on MHA plates for CFU counting. Culture broth from each well was inoculated on two plates, and the experiments were repeated three times.

\section{Antibiofilm assay}

MBICs and MBECs were determined as previously described ${ }^{46,60,61}$. The time-course biofilm formation on MRSA cells is shown in Fig. S2b. An overnight culture of test strains was diluted into approximately $10^{7}$ $\mathrm{CFU} / \mathrm{mL}$ with $\mathrm{LB}$ and $0.5 \%$ glucose and treated with various concentrations of testing compounds in 96 well cell-culture plates. There plates were then incubated at $37^{\circ} \mathrm{C}$ for $24 \mathrm{~h}$ and rinsed twice with $1 \times \mathrm{PBS}$ to remove non-adhering and planktonic cells. After rinsing, MTT staining assay was conducted to measure viable cells in the biofilms because MTT can react with activated succinate dehydrogenase in viable cell mitochondria to form blue-violet formazan, which can be read at $570 \mathrm{~nm}$ after dissolving in DMSO. $\mathrm{MBIC}_{50}$ and $\mathrm{MBIC}_{90}$ were defined as the lowest concentration required to inhibit $50 \%$ and $90 \%$ of biofilm formation, respectively.

For MBEC assay, an overnight culture of test strains was incubated for $24 \mathrm{~h}$ in 96 -well cell-culture plates to form mature biofilm before twice rinsing with $1 \times P B S$ and compound treatment. After 24 hs incubation at $37^{\circ} \mathrm{C}$, each well was rinsed twice with $1 \times P B S$, and $\mathrm{OD}_{570 \mathrm{~nm}}$ was recorded after MTT assay as described above. The lowest concentration of a compound resulting in $50 \%$ decreases in $\mathrm{OD}_{570 \mathrm{~nm}}$ were recorded as $\mathrm{MBEC}_{50}$. Biofilm inhibition/eradication efficiency was calculated using the following equation: Biofilm inhibition/eradication (\%) $=\left[1-\left(\mathrm{OD}_{570 \mathrm{~nm}}\right.\right.$ of test compound $) /\left(\mathrm{OD}_{570 \mathrm{~nm}}\right.$ of control $\left.)\right] \times$ $100 \%$. Experiments were performed in triplicate and repeated three times.

\section{Biofilm eradication monitoring and resistance study}

Mature biofilms of MRSA ATCC 43300 were first grown in 96-well cell-culture plates and treated with various concentrations of elasnin as described above. Plates were then collected after $0,3,6,12,18$ and $24 \mathrm{~h}$ treatment and $\mathrm{OD} 57 \mathrm{n}_{\mathrm{nm}}$ were recorded after rinse and MTT assay. To assess the resistance development risks of elasnin, resistance study was conducted as previously described ${ }^{62}$. MRSA ATCC 43300 were treated with elasnin, vancomycin and ciprofloxacin at final concentrations of $0.5 \times, 1 \times, 2 \times, 4 \times$, and $8 \times \mathrm{MIC}$ in the MIC assays as described above. After $24 \mathrm{~h}$ of incubation at $37^{\circ} \mathrm{C}$, the MICs were recorded and $1 \mu \mathrm{L}$ aliquots from the culture with the second-highest antibiotic concentration that showed visible growth were diluted 1000 times in MHB for the subsequent assay. This process was repeated for 45 days, and the final MIC was confirmed by the MIC assay. Experiment was performed in quadruplicate and on each day.

\section{Cytotoxicity test}


HT22 and Neuro2a (N2a) cells were used in the MTT assay to test the cytotoxicity of the compounds. Cells were grown in DMEM with $10 \% \mathrm{FBS}$ and $1 \%$ penicillin-streptomycin at $37^{\circ} \mathrm{C}$ with $5 \% \mathrm{CO}_{2}$. Then, $5 \times 10^{3}$ cells were seeded in each well of 96 -well plates and cultured for $24 \mathrm{~h}$. After treating the the cells with different concentrations of the compounds dissolved in DMSO for another $24 \mathrm{~h}, 20 \mu \mathrm{L}$ of MTT (5 $\mathrm{mg} / \mathrm{ml}$ ) was added to each well and incubated for $4 \mathrm{~h}$ at $37^{\circ} \mathrm{C}$ before adding $100 \mu \mathrm{L}$ of DMSO to dissolve formazan. The absorbance was measured using the Multiskan ${ }^{\text {TM }} \mathrm{FC}$ microplate photometer at $570 \mathrm{~nm}$. $\mathrm{IC}_{50}$ data were analysed with GraphPad Prism software.

\section{CLSM observation with biofilm staining}

Biofilms were grown on glass cover slides as those described for the MBIC and MBEC assays. Treated biofilms were then rinsed twice with $1 \times$ PBS and stained with FilmTracer ${ }^{\mathrm{TM}} \mathrm{FM}{ }^{\circledR}$ 1-43 green biofilm cell stain and FilmTracer ${ }^{T M}$ SYPRO ${ }^{\circledR}$ Ruby Biofilm Matrix Stain at room temperature for 30 min in the dark. A Leica Sp8 confocal microscope was used to observe cells and matrix in the biofilm at $488 \mathrm{~nm}$.

To visualise the changes in biofilm matrix components after elasnin treatment, biofilms were prepared as described above in the MBEC assays and stained with TOTO ${ }^{\text {TM}}-1$ lodide and Concanavalin A to observe eDNA and polysaccharides within the biofilm matrix according to the manufacturer's instruction. A Zeiss LSM 710 confocal microscope was used for observing and ImageJ was used for quantification.

\section{Total RNA extraction and transcriptomic analysis}

Overnight cultures of $10^{7} \mathrm{CFU} / \mathrm{mL}$ MRSA cells were inoculated into TSB complemented with $0.5 \%$ glucose (TSBG) at $37^{\circ} \mathrm{C}$ to get mature biofilms. After $24 \mathrm{~h}$ of incubation, mature biofilms were rinsed with $1 \times$ PBS twice and treated with $5 \mu \mathrm{g} / \mathrm{mL}$ elasnin or media. Biofilm and released cells were collected at 6 and $12 \mathrm{~h}$ and RNA was immediately stabilised with RNAprotect Bacteria Reagent (Qiagen, Hilden, German) according to the manufacturer's protocol. Total RNA was then extracted with RNeasy PowerBiofilm Kit (Qiagen, Hilden, German) and sequenced using Illumina Novaseq platform with 150bp short-insert library to generate $2 \mathrm{~Gb}$ paired-end reads for each sample. The raw reads were trimmed with Trimmomatic $v 0.36^{63}$ to remove adapters and low-quality bases with the setting ILLUMINACLIP: TruSeq3PE.fa:2:30:10 and then mapped to the $S$. aureus ATCC 43300 genome (https://genomes.atcc.org/genomes/79691302ed634fef?_ga=2.259377226.1584810311.16164833001172888945.1616483300 ) by using Bowtie2 v2.3.5 ${ }^{64}$. Salmon v.0.13.1 ${ }^{65}$ was used to quantify the abundance of successfully mapped transcripts, and differential expression analysis was conducted using Perl scripts align_and_estimate_abundance.pl and run_DE_analysis.pl under edge ${ }^{66}$ method in Trinity v2.8.5 ${ }^{67,68}$ toolkits. Transcripts with false discovery rates $<0.05$ and an absolute fold-change value $>2$ were defined as DEGs.

\section{Sample preparation for proteomics analysis}

Preformed biofilms were prepared the same way as those described for transcriptome analysis and then treated with $5 \mu \mathrm{g} / \mathrm{mL}$ elasnin (or media for control) for 2,6 , and $12 \mathrm{~h}$ followed by rinsing twice. Biofilm 
matrix and total proteins were extracted as previously described ${ }^{69}$ with slight modification. In a typical procedure, biofilms were collected from the bottom of the dish and washed with washing buffer comprising $10 \mathrm{mM}$ Tris- $\mathrm{HCl}(\mathrm{pH} 8.0)$ and protease inhibitor cocktail (Sigma-Aldrich) followed by centrifugation at $5,000 \mathrm{~g}$ for $10 \mathrm{~min}$. The pellet was dissolved in a matrix-extraction buffer comprising 10 $\mathrm{mM}$ Tris- $\mathrm{HCl}(\mathrm{pH} 8.0), 1 \mathrm{M} \mathrm{NaCl}$, and protease-inhibitor cocktail followed by incubation at $25^{\circ} \mathrm{C}$ for $30 \mathrm{~min}$ with gentle rotation. The mixture was centrifuged at $5,000 \mathrm{~g}$ for $10 \mathrm{~min}$ after incubation, and the supernatant was collected as the biofilm-matrix protein. To extract the total protein, the pellet was lysed with B-PER ${ }^{\mathrm{TM}}$ bacterial protein extraction reagent (Thermo Scientific) according to the manufacturer's instructions and sonicated with a Q125 Sonicator (Qsonica) set at 65\% amplitude (five blasts each lasting $15 \mathrm{~s}$ with $30 \mathrm{~s}$ pauses). The supernatant was collected as the total protein after centrifugation. For all proteomics experiments, three biological replicates were performed for each sample including the control sample.

Collected proteins were desalted with Thermo Pierce C18 spin tips and digested with trypsin (Pierce ${ }^{\text {TM }}$ Trypsin Protease, MS Grade) before injecting into the Bruker timsTOF Pro Mass-spectrometer (Bruker Headquarters Billerica, MA, US) with capitve apray ion source. Approximately $200 \mathrm{ng}$ of the digested protein was injected into the Bruker nanoElute system and separated on a C18 column (ionoptiks Aurora UPLC column, Part no. AUR2-25075C18A-CSI) that was eluted with a 30 min gradient of $2-95 \%$ aqueous acetonitrile containing $0.1 \%$ formic acid at a flow rate of $0.3 \mu \mathrm{L} / \mathrm{min}$. The $\mathrm{m} / \mathrm{z}$ range acquired in the MS full scan was $100-1700 \mathrm{Da}$.

\section{Sequence database searching and label-free quantification of proteomics data}

The generated raw data were converted to mgf files by Bruker Compass DataAnalysis, and subsequently converted to mzML files by msconvert of the ProteoWizard ${ }^{70}$. The mzML files were searched using Comet (version 2016.01 rev.2) ${ }^{71}$ with a custom database. In a typical procedure, the genome sequence of

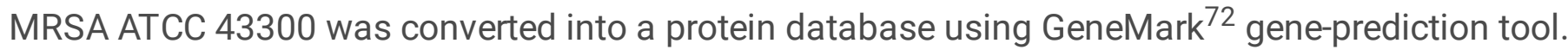
Proteins were then annotated using BLASTp from NCBI using MRSA NCTC 8325 as the protein database. The sequences of common contaminants such as trypsin and human keratins, as well as decoy sequences generated by shuffling amino acid sequences between tryptic cleavage sites, were added to the database. The decoy sequences in the database were used for the false FDR estimation of identified peptides. The search parameters criteria were set as follows: $15 \mathrm{ppm}$ peptide mass tolerance, monoisotopic mass type, fully digested enzyme termini, 0.05 amu fragment bin tolerance, $0 \mathrm{amu}$ fragment bin offset, carbamidomethylated cysteine, and oxidated methionine as the fixed and variable modifications, respectively. Search results from Comet were processed using PeptideProphet ${ }^{73}$, iProphet, and ProteinProphet of the Trans-Proteomics Pipeline ${ }^{74}$ in the decoy-assisted non-parametric mode. Every mzML run was analysed independently. Protein identifications were filtered at a FDR of 0.01 as predicted by ProteinProphet.

Label-free quantification of proteomics data was accomplished by spectral counting. Search results from the two technical replicates of each biological replicate were combined, and proteins identified in at least 
two out of three biological replicates were used for label-free quantification by spectral counting. Proteins were quantified using the normalised spectral-abundance factor $(\mathrm{NSAF})^{75}$, where the number of peptidespectrum matches (PSMs) for each protein divided by the length of the corresponding protein was normalised to the total number of PSMs divided by the lengths of protein for all identified proteins. The DEPs were filtered by the following cutoff: average spectral counts of at least three, $p$-value for Student's $t$ test on the NSAF values was lower than 0.05 , and the fold changes were higher or lower than \pm 1.5 -fold. Moreover, only unique proteins detected in the treatment samples or the control samples were retained for analysis as they were also likely to have increased/decreased expression owing to elasnin treatment. To minimise false positives, we further limit our attention to only uniquely detected proteins with spectral counts greater than 4 . Here, we assume that these unique proteins with sufficiently high spectral counts were also induced/upregulated (if detected only in treatment samples and not in control samples) or repressed/downregulated (if detected only in control samples and not in treatment samples).

\section{SEM analysis of biofilms treated with elasnin}

Samples for SEM analysis were prepared as previously described with a little modification ${ }^{76,77}$. Preformed biofilms on a copper strip surface were treated with elasnin $(5 \mu \mathrm{g} / \mathrm{mL})$ or TSBG for $6 \mathrm{~h}$ followed by overnight fixation with $4 \%(\mathrm{v} / \mathrm{v})$ glutaraldehyde under $4{ }^{\circ} \mathrm{C}$. Thereafter, biofilms were dehydrated in a graded ethanol series $(30 \%, 50 \%, 70 \%, 90 \% \mathrm{v} / \mathrm{v}$ with distilled water and three times with $100 \%$ ethanol, 10 min each step) followed by air drying. Samples were then gold coated using a gold coater Scancoat Six (Edwards, Irvine, CA, USA) and observed using a SEM (JSM-6390, JEOL, Akishima, Tokyo, Japan).

\section{Bioinformatics Analysis}

PCA was performed to determine the correlation between individuals and expression level of transcripts on $\mathrm{R}$, using DESeq $2^{78}$. Functional annotation, enrichment analysis of DEGs/DEPs was performed using The Database for Annotation, Visualization and Integrated Discovery (DAVID) v6.879,80 (ease=0.01). Cluster analysis was constructed to reveal the similarity of gene expression between control and elasnintreated groups based on Bray-Curtis distance matrix in the software PAST (version 2.0) ${ }^{81}$. To construct the interaction network between the DEGs/DEPs, STRING $v 11^{82}$ was used to predict the protein-protein interactions.

\section{Transcription inhibition and complementation of DEGs in the MRSA}

The expression of upregulated DEGs was inhibited using CRISPR/Cas9 transcription-inhibition system pCasiSA, whereas genes downregulated by elasnin were complemented with a tetracycline-inducible expression vector pRMC2 in the wild-type MRSA ATCC 43300 . All plasmids, bacterial strains, and primers used in this study are listed in Tables S3 and S4. pRMC2 was a gift from Tim Foster ${ }^{83}$ (Addgene plasmid \#68940; http://n2t.net/addgene:68940; RRID: Addgene 68940). pCasiSA was constructed by mutating 
pCasSA plasmid as previously described ${ }^{84}$ and pCasSA was a gift from Quanjiang Ji (Addgene plasmid \#98211; http://n2t.net/addgene:98211; RRID: Addgene_98211).

Constructed plasmid was transported into the wild-type MRSA ATCC43300 by Electroporation. In a typical procedure, competent cells were prepared as previously described ${ }^{8383}$ and stored at $-80{ }^{\circ} \mathrm{C}$. For electroporation, $50 \mu \mathrm{L}$ of competent cells were thawed on ice for $10 \mathrm{~min}$ and mixed with 1-2 $\mu \mathrm{g}$ of plasmid, and transferred into a $1 \mathrm{~mm}$ electroporation cuvette (Bio-Rad, Hercules, CA, USA). Cells were then pulsed at $2.5 \mathrm{kV}, 100 \Omega$, and $25 \mu \mathrm{F}$ and incubated in $1 \mathrm{~mL}$ of TSB at $30^{\circ} \mathrm{C}$ for $1 \mathrm{~h}$ followed by plating on a TSB agar plate containing $7.5 \mu \mathrm{g} / \mathrm{mL}$ chloramphenicol. The plates containing pRMC2 plasmid were incubated at $37{ }^{\circ} \mathrm{C}$, whereas plates with pCasiSA plasmid were incubated at $30^{\circ} \mathrm{C}$. Strains containing different plasmids were then used for $\mathrm{MBEC}$ and $\mathrm{MBIC}$ assay as described above (all strains containing pCasiSA plasmid were incubated at $30{ }^{\circ} \mathrm{C}$ throughout the entire assay).

\section{Quantitative real-time PCR}

A $3 \mathrm{~mL}$ overnight culture of mutant MRSA strains $(0.2 \mu \mathrm{g} / \mathrm{mL}$ anhydrotetracycline was added in complemented strains) was harvested, stabilized, and total RNA was extracted as described above. cDNA was then synthesised with RevertAid H Minus First-Strand cDNA Synthesis Kit after the removal of genomic DNA using DNase I (Thermo Fisher Scientific Inc., Waltham, MA, USA) followed by quantification on a Roche Diagnostics GmbH LightCycler 480 Instrument II Realtime PCR System using SYBR Green RTPCR Reagents Kit (Applied Biosystems) with the following procedures: (1) polymerase activation at $95^{\circ} \mathrm{C}$ for $10 \mathrm{~min}$, and (2) annealing and extension at $55^{\circ} \mathrm{C}$ for $1 \mathrm{~min}$ for a total of 40 cycles. The specificity of primer pairs for PCR amplification was checked by the melting-curve method. Two biological replicates and three technical replicates were performed for each sample, and the relative gene-expression level was calculated based on the $2 \Delta \Delta \mathrm{Ct}$ using $g y r B$ as the internal-reference gene.

\section{Statistical analyses}

Statistical analyses for all data were performed using the GraphPad Prism 8.0.2 software and Microsoft Excel 2012 Edition (Microsoft, Redmond, WA, USA).

\section{Data availability}

The RNA-seq data used in the present study were deposited to GeneBank with the accession codes PRJNA740277, and the proteomics data were deposited to the ProteomeXchange through the PRIDE repository with the dataset identifier PXD026836.

\section{References}

1. Vert, M. et al. Terminology for biorelated polymers and applications (IUPAC Recommendations 2012). Pure and Applied Chemistry 84, 377-410 (2012). 
2. Flemming, H. C. et al. Biofilms: an emergent form of bacterial life. Nature Review Microbiology 14 , 563-575 (2016).

3. Flemming, H. C. \& Wingender, J. The biofilm matrix. Nature Review Microbiology 8, 623-633 (2010).

4. Stewart, P. S. \& William Costerton, J. Antibiotic resistance of bacteria in biofilms. The Lancet 358, 135-138 (2001).

5. Mah, T. F. \& O'Toole, G. A. Mechanisms of biofilm resistance to antimicrobial agents. Trends in Microbiology 9, 34-39 (2001).

6. Hall, C. W. \& Mah, T. F. Molecular mechanisms of biofilm-based antibiotic resistance and tolerance in pathogenic bacteria. FEMS Microbiology Review 41, 276-301, (2017).

7. Nickel, J., Ruseska, I., Wright, J. \& Costerton, J. Tobramycin resistance of Pseudomonas aeruginosa cells growing as a biofilm on urinary catheter material. Antimicrobial Agents and Chemotherapy 27 , 619 (1985).

8. Evans, R. C. \& Holmes, C. J. Effect of vancomycin hydrochloride on Staphylococcus epidermidis biofilm associated with silicone elastomer. Antimicrobial Agents and Chemotherapy 31, 889 (1987).

9. Romling, U. \& Balsalobre, C. Biofilm infections, their resilience to therapy and innovative treatment strategies. Joural of Internal Medicine 272, 541-561 (2012).

10. Archibald, L. K. \& Gaynes, R. P. Hospital-acquired infections in the United States: the importance of interhospital comparisons. Infectious Disease Clinics of North America 11, 245-255 (1997).

11. Potera, C. Forging a link between biofilms and disease. Science 283, 1837-1839(1999).

12. del Pozo, J. L. \& Patel, R. The challenge of treating biofilm-associated bacterial infections. Clinical Pharmacology \& Therapeutics, 82(2), 204-209 (2007).

13. Donlan, R. M. Biofilm formation: a clinically relevant microbiological process. Clinic Infectious Diseases 33, 1387-1392 (2001).

14. Rajendran, R. et al. Biofilm formation is a risk factor for mortality in patients with Candida albicans bloodstream infection - Scotland, 2012-2013. Clinical Microbiology and Infection 22, 87-93 (2016).

15. Lister, J. L. \& Horswill, A. R. Staphylococcus aureus biofilms: recent developments in biofilm dispersal. Frontiers in Cellular and Infection Microbiology 4, 178 (2014).

16. Moormeier, D. E. \& Bayles, K. W. Staphylococcus aureus biofilm: a complex developmental organism. Molecular Microbiology 104, 365-376 (2017).

17. Otto, M. Staphylococcal biofilms. Gram-positive Pathogens, 699-711 (2019).

18. Antunes, L. C. M. \& Ferreira, R. B. R. Biofilms and bacterial virulence. Reviews in Medical Microbiology 22, 12-16, (2011).

19. Alves, P. M. et al. Interaction between Staphylococcus aureus and Pseudomonas aeruginosa is beneficial for colonisation and pathogenicity in a mixed biofilm. Pathogens and Disease 76, fty003 (2018).

20. Bose, J. L., Lehman, M. K., Fey, P. D. \& Bayles, K. W. Contribution of the Staphylococcus aureus Atl AM and GL murein hydrolase activities in cell division, autolysis, and biofilm formation. PloS one 7, 
e42244 (2012).

21. Heilmann, C., Hussain, M., Peters, G. \& Götz, F. Evidence for autolysin-mediated primary attachment of Staphylococcus epidermidis to a polystyrene surface. Molecular Microbiology 24, 1013-1024 (1997).

22. Schlag, M. et al. Role of staphylococcal wall teichoic acid in targeting the major autolysin Atl. Molecular Microbiology 75, 864-873 (2010).

23. Clarke, S. R., Harris, L. G., Richards, R. G. \& Foster, S. J. Analysis of Ebh, a 1.1-megadalton cell wallassociated fibronectin-binding protein of Staphylococcus aureus. Infection and immunity 70, 6680 (2002).

24. Cheung, A. L., Nishina, K. A., Trotonda, M. P. \& Tamber, S. The SarA protein family of Staphylococcus aureus. The International Journal of Biochemistry \& Cell Biology 40, 355-361 (2008).

25. Coelho, L. R. et al. agr RNAlll divergently regulates glucose-induced biofilm formation in clinical isolates of Staphylococcus aureus. Microbiology 154, 3480-3490 (2008).

26. Haag, A. F. \& Bagnoli, F. The role of two-component signal transduction systems in Staphylococcus aureus virulence regulation. Current Topics in Microbiol Immunology 409, 145-198 (2017).

27. Boisset, S. et al. Staphylococcus aureus RNAlll coordinately represses the synthesis of virulence factors and the transcription regulator Rot by an antisense mechanism. Genes Development 21, 1353-1366 (2007).

28. Queck, S. Y. et al. RNAlll-independent target gene control by the AGR quorum-sensing system: insight into the evolution of virulence regulation in Staphylococcus aureus. Molecular Cell 32, 150-158 (2008).

29. Monteiro, J. M. et al. Cell shape dynamics during the staphylococcal cell cycle. Nature Communications 6, 1-12 (2015).

30. Zielińska, A. et al. LytM factors affect the recruitment of autolysins to the cell division site in Caulobacter crescentus. Molecular Microbiology 106, 419-438 (2017).

31. Chunhua, M. et al. The expression of LytM is down-regulated by RNAlll in Staphylococcus aureus. Journal of Basic Microbiology 52, 636-641 (2012).

32. Cheung, A. L., Nishina, K. \& Manna, A. C. SarA of Staphylococcus aureus binds to the SarA promoter to regulate gene expression. Journal of Bacteriology 190, 2239 (2008).

33. Beenken, K. E., Blevins, J. S. \& Smeltzer, M. S. Mutation of sarA in Staphylococcus aureus limits biofilm formation. Infection and Immunity 71, 4206 (2003).

34. Beenken, K. E. et al. Epistatic relationships between SarA and AGR in Staphylococcus aureus biofilm formation. PloS one 5, e10790 (2010).

35. Jenul, C. \& Horswill, A. R. Regulation of Staphylococcus aureus virulence. Microbiology Spectrumetry 7, (2019).

36. Lauderdale, K. J., Boles, B. R., Cheung, A. L. \& Horswill, A. R. Interconnections between sigma B, agr, and proteolytic activity in Staphylococcus aureus biofilm maturation. Infection and Immunity 77, 
1623-1635 (2009).

37. Kong, K.-F., Vuong, C. \& Otto, M. Staphylococcus quorum sensing in biofilm formation and infection. International Journal of Medical Microbiology 296, 133-139 (2006).

38. O'Gara, J. P. Ica and beyond: biofilm mechanisms and regulation in Staphylococcus epidermidis and Staphylococcus aureus. FEMS Microbiol Lett 270, 179-188 (2007).

39. Vasudevan, R. Agr/sarA: molecular switches of biofilm regulation in Staphylococcus aureus. Journal of Microbiology \& Experimentation 7, 17-18 (2019).

40. Gillings, M. R. \& Stokes, H. Are humans increasing bacterial evolvability? Trends in Ecology \& Evolution 27, 346-352 (2012).

41. Gillings, M. R. \& Paulsen, I. T. Microbiology of the Anthropocene. Anthropocene 5, 1-8 (2014).

42. Penesyan, A., Gillings, M. \& Paulsen, I. T. Antibiotic discovery: combatting bacterial resistance in cells and in biofilm communities. Molecules 20, 5286-5298 (2015).

43. Koo, H., Allan, R. N., Howlin, R. P., Stoodley, P. \& Hall-Stoodley, L. Targeting microbial biofilms: current and prospective therapeutic strategies. Nature Review Microbiology 15, 740-755 (2017).

44. Li, X. H. \& Lee, J. H. Antibiofilm agents: A new perspective for antimicrobial strategy. Joural Microbiology 55, 753-766 (2017).

45. Dias, D. A., Urban, S. \& Roessner, U. A historical overview of natural products in drug discovery. Metabolites 2, 303-336 (2012).

46. Long, L. et al. Discovery of antibiofilm activity of elasnin against marine biofilms and its application in the marine antifouling coatings. Marine Drugs 19, 19 (2021).

47. Holmes, A. H. et al. Understanding the mechanisms and drivers of antimicrobial resistance. The Lancet 387, 176-187 (2016).

48. Martinez, J. L. Environmental pollution by antibiotics and by antibiotic resistance determinants. Environmental Pollution 157, 2893-2902 (2009).

49. Aminov, R. I. The role of antibiotics and antibiotic resistance in nature. Environmental Microbiology 11, 2970-2988 (2009).

50. Ohno, H., Saheki, T., Awaya, J., Nakagawa, A. \& Omura, S. Isolation and characterization of elasnin, a new human granulocyte elastase inhibitor produced by a strain of Streptomyces. J Antibiot (Tokyo) 31, 1116-1123 (1978).

51. Oscarsson, J., Tegmark-Wisell, K. \& Arvidson, S. Coordinated and differential control of aureolysin (aur) and serine protease (sspA) transcription in Staphylococcus aureus by sarA, rot and agr (RNAIII). International Journal of Medical Microbiology 296, 365-380 (2006).

52. O'Gara, J. P. ica and beyond: biofilm mechanisms and regulation in Staphylococcus epidermidis and Staphylococcus aureus. FEMS Microbiology Letters 270, 179-188 (2007).

53. Rice, K. C. et al. The cidA murein hydrolase regulator contributes to DNA release and biofilm development in Staphylococcus aureus. Proceedings of the National Academy of Sciences 104, 8113-8118 (2007). 
54. Gimza, B. D., Larias, M. I., Budny, B. G. \& Shaw, L. N. Mapping the global network of extracellular protease regulation in Staphylococcus aureus. mSphere 4, e00676-00619 (2019).

55. Sadykov, M. R. \& Bayles, K. W. The control of death and lysis in staphylococcal biofilms: a coordination of physiological signals. Current Opinion in Microbiology 15, 211-215 (2012).

56. Tamber, S. \& Cheung, A. L. SarZ promotes the expression of virulence factors and represses biofilm formation by modulating SarA and agr in Staphylococcus aureus. Infection and Immunity 77, 419428 (2009).

57. Fechter, P., Caldelari, I., Lioliou, E. \& Romby, P. Novel aspects of RNA regulation in Staphylococcus aureus. FEBS letters 588, 2523-2529 (2014).

58. Ballal, A., Ray, B. \& Manna, A. C. sarZ, a sarA family gene, is transcriptionally activated by MgrA and is involved in the regulation of genes encoding exoproteins in Staphylococcus aureus. Journal of Bacteriology 191, 1656 (2009).

59. Kresovic, D., Schempp, F., Cheikh-Ali, Z. \& Bode, H. B. A novel and widespread class of ketosynthase is responsible for the head-to-head condensation of two acyl moieties in bacterial pyrone biosynthesis. Beilstein Journal of Organic Chemistry 11, 1412-1417 (2015).

60. Yin, Q. et al. Butenolide, a marine-derived broad-spectrum antibiofilm agent against both Grampositive and Gram-negative pathogenic bacteria. Marine Biotechnology (NY) 21, 88-98 (2019).

61. Nair, S., Desai, S., Poonacha, N., Vipra, A. \& Sharma, U. Antibiofilm activity and synergistic inhibition of Staphylococcus aureus biofilms by bactericidal protein P128 in combination with antibiotics. Antimicrobial Agents Chemother 60, 7280-7289 (2016).

62. Li, Y.-X., Zhong, Z., Zhang, W.-P. \& Qian, P.-Y. Discovery of cationic nonribosomal peptides as Gramnegative antibiotics through global genome mining. Nature Communications 9, 1-9 (2018).

63. Bolger, A. M., Lohse, M. \& Usadel, B. Trimmomatic: a flexible trimmer for Illumina sequence data. Bioinformatics 30, 2114-2120 (2014).

64. Langmead, B. \& Salzberg, S. L. Fast gapped-read alignment with Bowtie 2. Nature Methods 9, 357 (2012).

65. Patro, R., Duggal, G., Love, M. I., Irizarry, R. A. \& Kingsford, C. Salmon provides fast and bias-aware quantification of transcript expression. Nature Methods 14, 417-419 (2017).

66. Robinson, M. D., McCarthy, D. J. \& Smyth, G. K. edgeR: a Bioconductor package for differential expression analysis of digital gene expression data. Bioinformatics 26, 139-140 (2010).

67. Grabherr, M. G. et al. Trinity: reconstructing a full-length transcriptome without a genome from RNASeq data. Nature Biotechnology 29, 644 (2011).

68. Haas, B. J. et al. De novo transcript sequence reconstruction from RNA-seq using the Trinity platform for reference generation and analysis. Nature Protocols 8, 1494-1512 (2013).

69. Sugimoto, S. et al. Staphylococcus epidermidis Esp degrades specific proteins associated with Staphylococcus aureus biofilm formation and host-pathogen interaction. Journal of Bacteriology 195, 1645-1655 (2013). 
70. Kessner, D., Chambers, M., Burke, R., Agus, D. \& Mallick, P. ProteoWizard: open source software for rapid proteomics tools development. Bioinformatics 24, 2534-2536 (2008).

71. Eng, J. K., Jahan, T. A. \& Hoopmann, M. R. Comet: an open-source MS/MS sequence database search tool. Proteomics 13, 22-24 (2013).

72. Lukashin, A. V. \& Borodovsky, M. GeneMark. hmm: new solutions for gene finding. Nucleic Acids Research 26, 1107-1115 (1998).

73. Keller, A., Nesvizhskii, A. I., Kolker, E. \& Aebersold, R. Empirical statistical model to estimate the accuracy of peptide identifications made by MS/MS and database search. Analytical Chemistry 74, 5383-5392 (2002).

74. Deutsch, E. W. et al. A guided tour of the trans-proteomic pipeline. Proteomics 10, 1150-1159 (2010).

75. Paoletti, A. C. et al. Quantitative proteomic analysis of distinct mammalian mediator complexes using normalized spectral abundance factors. Proceedings of the National Academy of Sciences 103, 18928-18933 (2006).

76. Boudjemaa, R. et al. Direct observation of the cell-wall remodeling in adhering Staphylococcus aureus 27217: An AFM study supported by SEM and TEM. The Cell Surface 5, 100018 (2019).

77. Kong, C. et al. Suppression of Staphylococcus aureus biofilm formation and virulence by a benzimidazole derivative, UM-C162. Scientific reports 8, 1-16 (2018).

78. Love, M., Anders, S. \& Huber, W. Differential analysis of count data-the DESeq2 package. Genome Biology 15, 10.1186 (2014).

79. Sherman, B. T. \& Lempicki, R. A. Systematic and integrative analysis of large gene lists using DAVID bioinformatics resources. Nature Protocols 4, 44 (2009).

80. Huang, D. W., Sherman, B. T. \& Lempicki, R. A. Bioinformatics enrichment tools: paths toward the comprehensive functional analysis of large gene lists. Nucleic Acids Research 37, 1-13 (2009).

81. Hammer, Ø., Harper, D. A. \& Ryan, P. D. PAST: Paleontological statistics software package for education and data analysis. Palaeontologia electronica 4(1), 9 (2001).

82. Szklarczyk, D. et al. String v11: protein-protein association networks with increased coverage, supporting functional discovery in genome-wide experimental datasets. Nucleic Acids Research 47, D607-D613 (2019).

83. Corrigan, R. M. \& Foster, T. J. An improved tetracycline-inducible expression vector for Staphylococcus aureus. Plasmid 61, 126-129 (2009).

84. Chen, W., Zhang, Y., Yeo, W.-S., Bae, T. \& Ji, Q. Rapid and efficient genome editing in Staphylococcus aureus by using an engineered CRISPR/Cas9 system. Journal of the American Chemical Society 139, 3790-3795 (2017).

\section{Declarations}

\section{Acknowledgment}


This work was financially supported by the National Key R\&D Program of China (2018YFA0903200), the China Ocean Mineral Resources Research and Development Association (COMRRDA17SC01), the Hong Kong Branch of Southern Marine Science and Engineering Guangdong Laboratory (Guangzhou) (SMSEGL20SC01), a CRF grant from the HKSAR government (C6026-19G-A), the Key Special Project for Introduced Talents Team of Southern Marine Science and Engineering Guangdong Laboratory (Guangzhou) (GML2019ZD0409), and the Research Grant Council of the Hong Kong Special Administrative Region, and China (Grant No. 16102821).

\section{Competing interests}

Pei-Yuan QIAN, Lexin LONG, Yongxin LI, Ruojun WANG, and Ho Yin CHIANG were inventors in a Chinese Patent application (No.202010850564.X) and a U.S. Patent (US20210051956A1) filed by China Ocean Mineral Resources R\&D Association (COMRA) and the Hong Kong University of Science and Technology, which covers antibiofilm activity of elasnin and its related applications in treating the biofilm infections.

\section{Contributions}

L.L. designed and carried out the experiments, did transcriptomic and related bioinformatics analysis, interpreted the data, and prepared the manuscript. J.E.S. did the proteomic analysis, wrote related methods, and did revision of the manuscript. Y.X. did the PCA and bioinformatics analysis and wrote related methods. A.C did the cytotoxicity test, interpreted the data, and wrote related methods. R.W. did the cluster analysis and wrote related methods. J.J.M., W.H.W., and W.L. helped in the experiments and data interpretation. Y.-X.L. helped in experiment design. F.C. gave technical support. H.L. and P.-Y.Q. supervised this study, gave technical support and conceptual advice, and did the major edition of the manuscript. All authors reviewed and edited the manuscript.

\section{Tables}


Table 1. Bioassay results of crude extracts from 12 actinobacterial strains

\begin{tabular}{|c|c|c|c|c|}
\hline \multirow{2}{*}{ Strain } & \multicolumn{3}{|c|}{ Bioassay ${ }^{a}$} & \multirow[t]{2}{*}{ Identification } \\
\hline & $\underset{(\mu \mathrm{gI} / \mathrm{mL})}{\mathrm{MIC}}$ & MBIC $(\mu \mathrm{g} / \mathrm{mL})$ & MBEC $(\mu \mathrm{g} / \mathrm{mL})$ & \\
\hline $\begin{array}{c}\text { Streptomyces mobaraensis } \\
\text { DSM } 40847\end{array}$ & $<4$ & $<4$ & $<4$ & Elasnin \\
\hline $\begin{array}{l}\text { Nocardiopsis potens } \\
\text { DSM } 45234\end{array}$ & $<4$ & $>100$ & $>100$ & Xanthone \\
\hline $\begin{array}{c}\text { Streptomyces scabrisporus } \\
\text { DSM } 41855\end{array}$ & $<4$ & $>100$ & $>100$ & Hitachimycin \\
\hline $\begin{array}{c}\text { Streptomyces sulphureus } \\
\text { DSM } 40104\end{array}$ & $20-100$ & $>100$ & $>100$ & Resistomycin \\
\hline $\begin{array}{l}\text { Kutzneria albida } \\
\text { DSM } 43870\end{array}$ & $20-100$ & $>100$ & $>100$ & - \\
\hline $\begin{array}{c}\text { Streptomyces fulvissimus } \\
\text { DSM } 40593\end{array}$ & $>100$ & $>100$ & $>100$ & - \\
\hline $\begin{array}{c}\text { Streptomyces exfoliates } \\
\text { DSM } 41693\end{array}$ & $>100$ & $>100$ & $>100$ & - \\
\hline $\begin{array}{c}\text { Saccharothrix espanaensis } \\
\text { DSM } 44229\end{array}$ & $>100$ & $>100$ & $>100$ & - \\
\hline $\begin{array}{c}\text { Nocardiopsis synnemataformans } \\
\text { DSM } 44143\end{array}$ & $>100$ & $>100$ & $>100$ & - \\
\hline $\begin{array}{l}\text { Sciscionella marina } \\
\text { DSM } 45152\end{array}$ & $>100$ & $>100$ & $>100$ & - \\
\hline $\begin{array}{c}\text { Nonomuraea coxensis } \\
\text { DSM } 45129\end{array}$ & $>100$ & $>100$ & $>100$ & - \\
\hline $\begin{array}{l}\text { Streptomyces cattleya } \\
\text { DSM } 46488\end{array}$ & $>100$ & $>100$ & $>100$ & - \\
\hline
\end{tabular}

a All of the crude extracts were tested with Gram-negative bacteria E. coli and Gram-positive bacteria MRSA; the concentrations illustrated here represent the bioassay results of the most potent crude extract among all.

\section{Figures}


a

\begin{tabular}{ccc}
\hline $\begin{array}{c}\text { Bioactivities } \\
(\mu \mathrm{g} / \mathrm{mL})\end{array}$ & Van & Elasnin \\
\hline $\mathrm{MIC}$ & $0.625-1.25$ & $1.25-2.5$ \\
$\mathrm{MBC}$ & $10-50$ & $>100$ \\
$\mathrm{MBIC}_{90}$ & $1.25-2.5$ & $1.25-2.5$ \\
$\mathrm{MBEC}_{50}$ & $10-20$ & $0.625-1.25$ \\
\hline
\end{tabular}

b

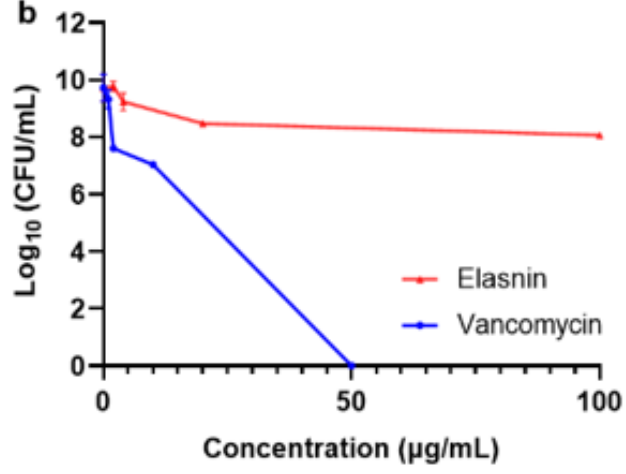

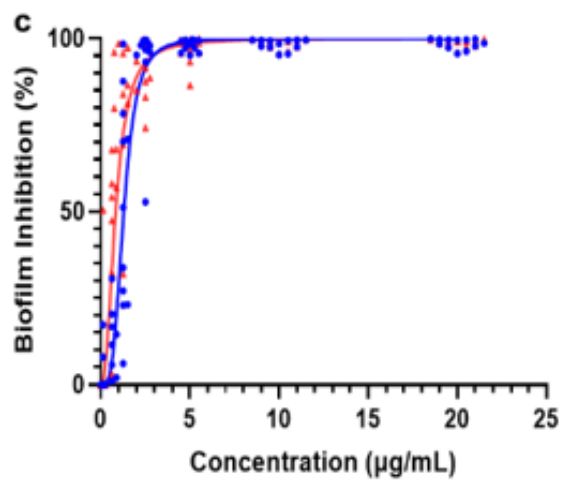
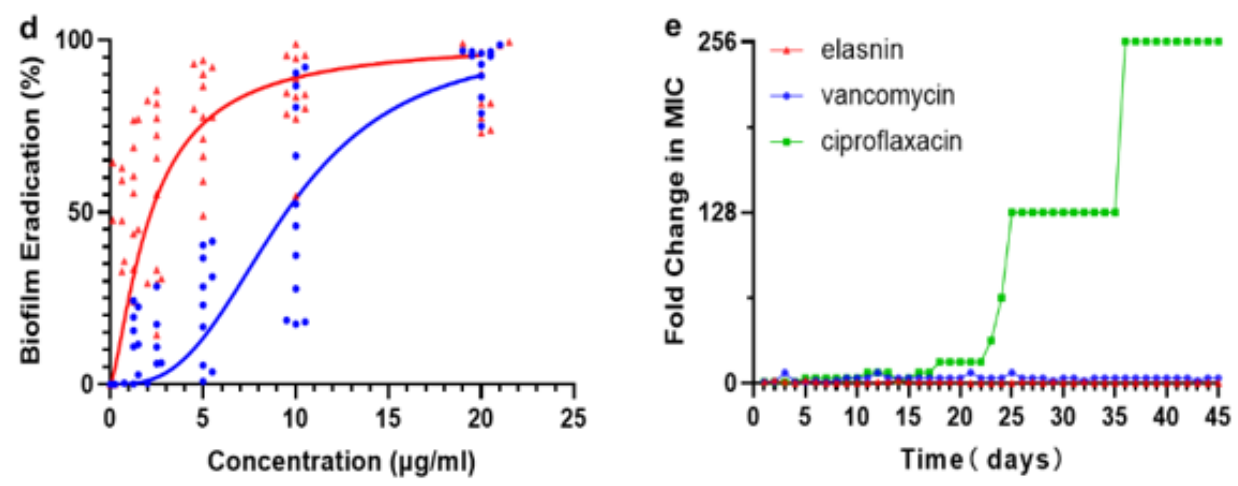

Figure 1

Bioactivities and resistance-development study of elasnin against MRSA. a Summary of MICs, MBCs, MBICs, and MBECs of MRSA towards vancomycin (Van) and elasnin. b Cell viability of MRSA after $24 \mathrm{~h}$ treatment with various concentrations of elasnin and vancomycin $(n=3)$. c Minimum concentration needed to inhibit $90 \%$ of biofilm formation ( $n=12$ ). d Minimum concentration needed to eradicate $50 \%$ of pre-formed biofilms $(n=12)$. e Fold change in MICs towards elasnin, vancomycin and ciprofloxacin after 45 -days of exposure under sub-inhibitory concentrations of the respective antimicrobials $(n=3)$. Points below $0 \%$ are not shown in the figure. 
(1)

a

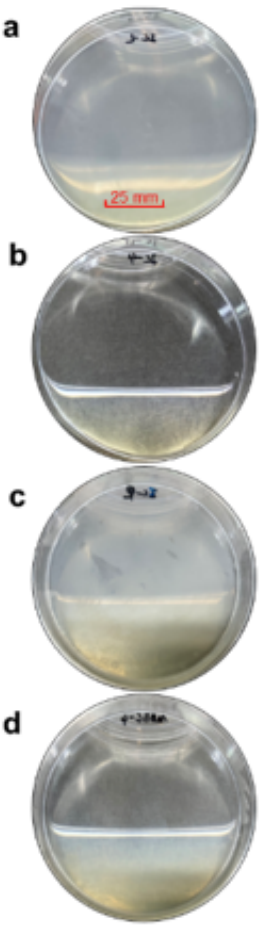

(2)

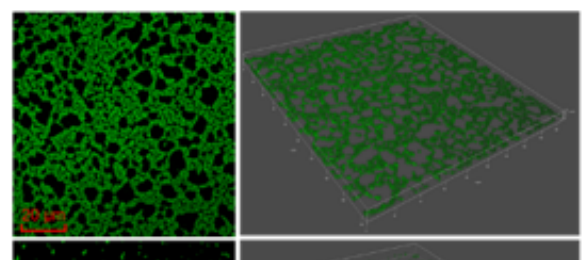

(4)

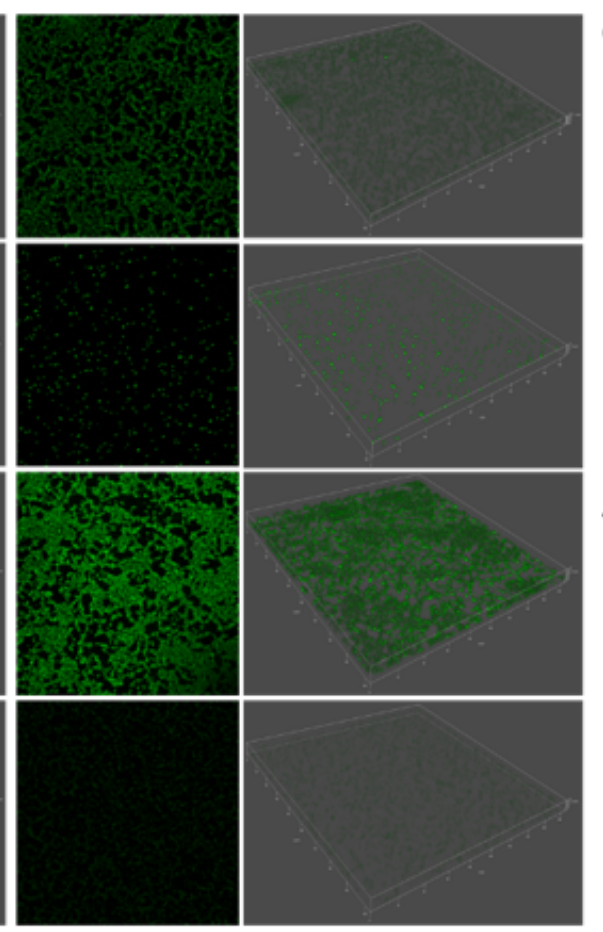

(5)
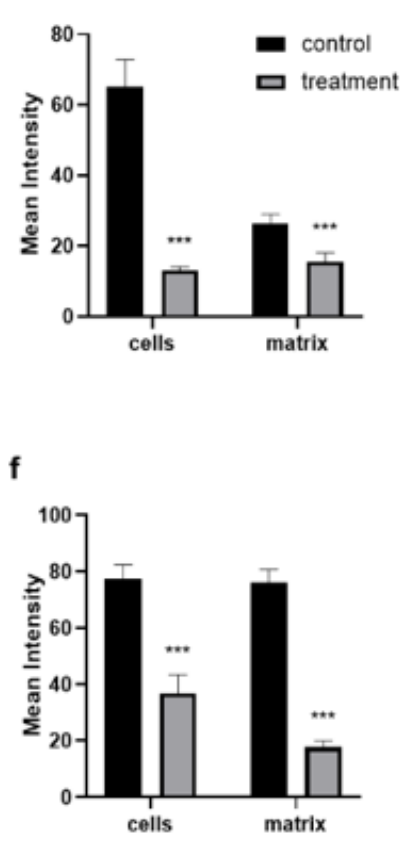

Figure 2

Comparisons between elasnin's effect on MRSA biofilm cells and matrix. a Image of the biofilms after incubation for $24 \mathrm{~h}$ (control). b Image of the biofilms after incubation for $24 \mathrm{~h}$ with elasnin 4 $\mu \mathrm{g} / \mathrm{mL}$ (treatment). c Image of the pre-formed biofilms after another incubation for $18 \mathrm{~h}$ (control). $\mathrm{d}$ Image of the pre-formed biofilms after another incubation for $18 \mathrm{~h}$ with elasnin treatment at a concentration of 4 $\mu \mathrm{g} / \mathrm{mL}$ (treatment). e Quantitative analysis of confocal images acquired in biofilm-inhibition assay and $\mathrm{f}$ biofilm-eradication assay. Differences between different groups were calculated by student's t-test and

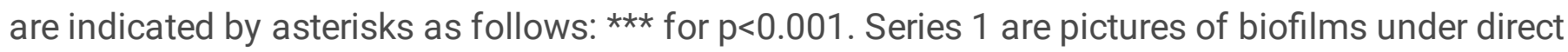
observation. Series 2 and 3 are two- and three-dimensional confocal images of biofilm cells stained with FilmTracer $^{T M} F M \circledR 1-43$ green biofilm cell stain. Series 4 and 5 were 2D and 3D images of biofilm matrix stained by FilmTracer ${ }^{\mathrm{TM}}$ SYPRO ${ }^{\circledR}$ Ruby Biofilm Matrix Stain, respectively. Confocal images were acquired under the same conditions, and quantitative analysis was conducted using Leica Application Suite $X$ based on the relative fluorescence of 3D confocal images. 
a
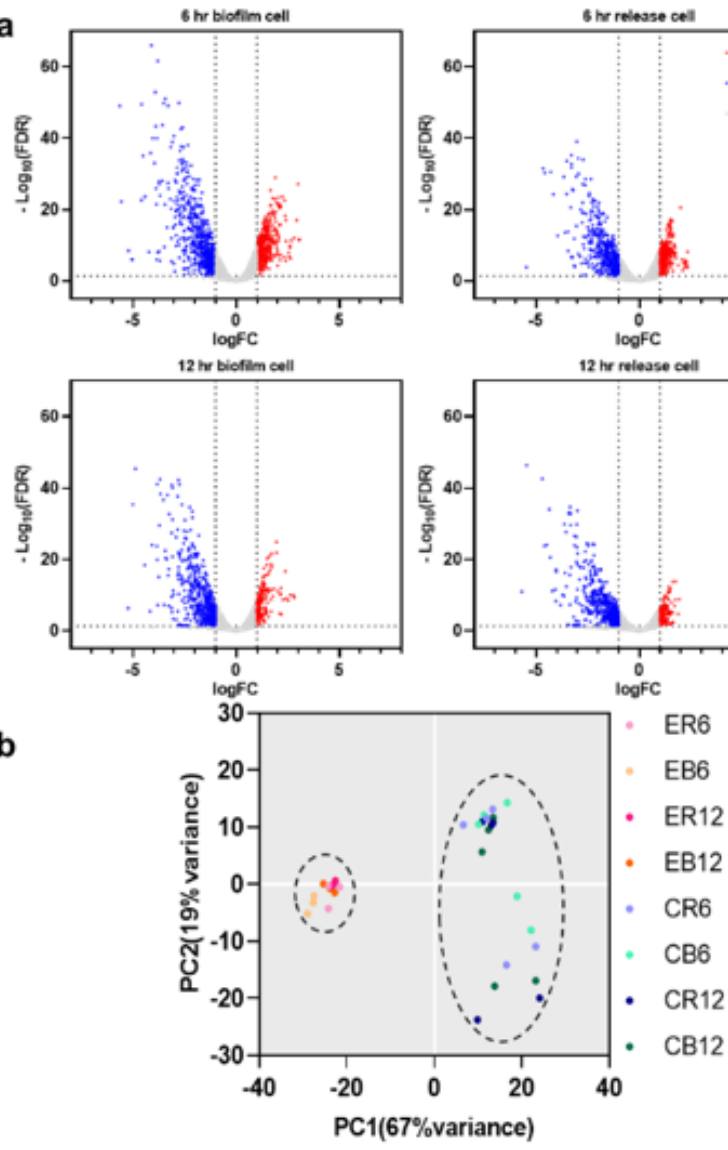

C
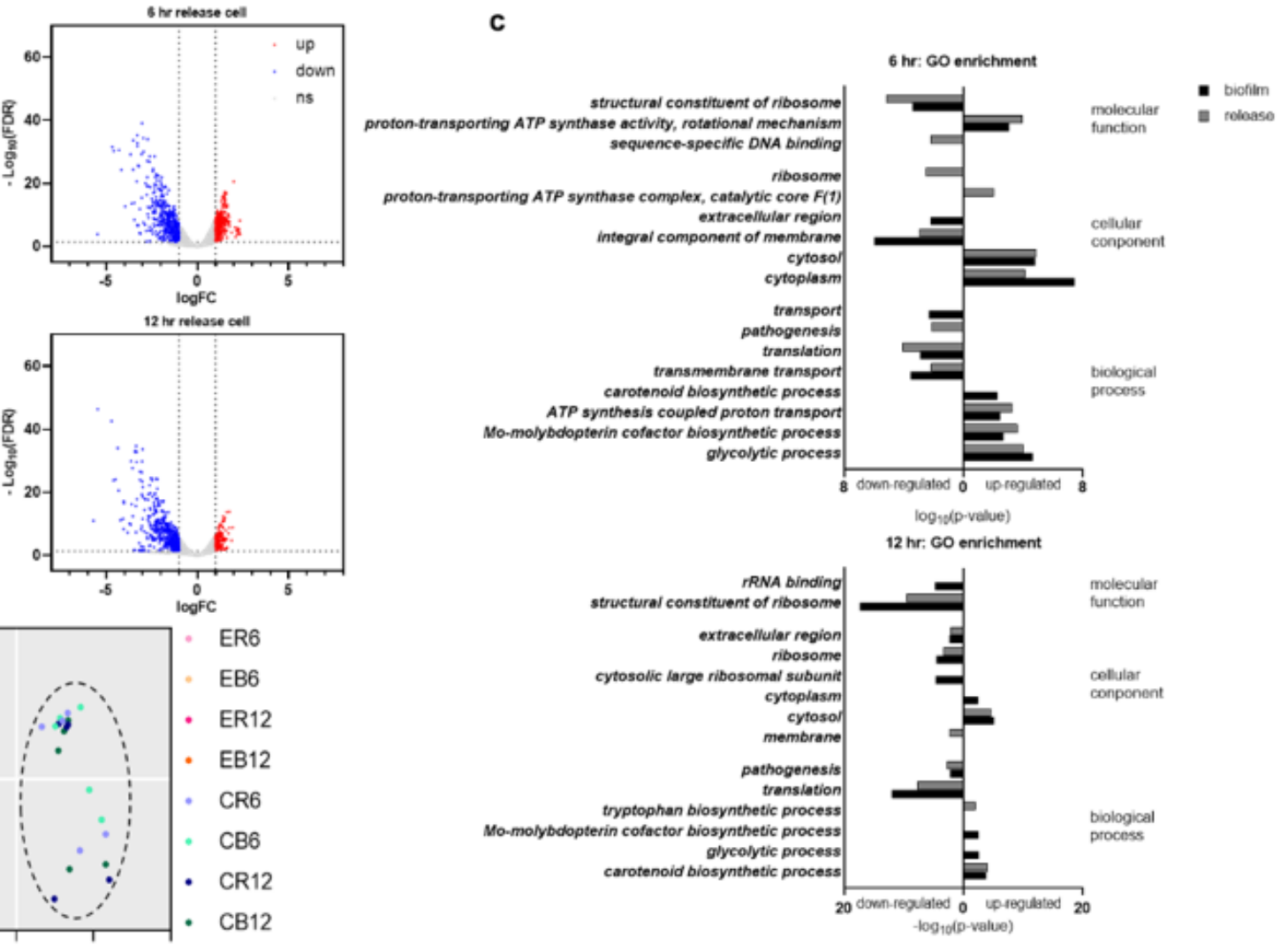

\section{Figure 3}

Changes in gene expression of MRSA cells after elasnin treatment. a Volcano plot of RNA-seq profiles of MRSA cells (up: upregulated, corresponding to the red dots; down: downregulated, corresponding to the blue dots; ns: not significantly changed, corresponding to the gray dots). b Principal component analysis (PCA) of RNA-seq samples (treated with elasnin and untreated). ER: cells released from elasnin-treated biofilms; CR: cells naturally released from the biofilms; EB: elasnin-treated biofilms cells; CB: biofilm cells. Numbers following the letters indicated the duration of elasnin treatment (in hour). c Gene ontology (GO) enrichment analysis of differentially expressed genes (in biofilm and released cells, marked by black and gray bars, respectively). 


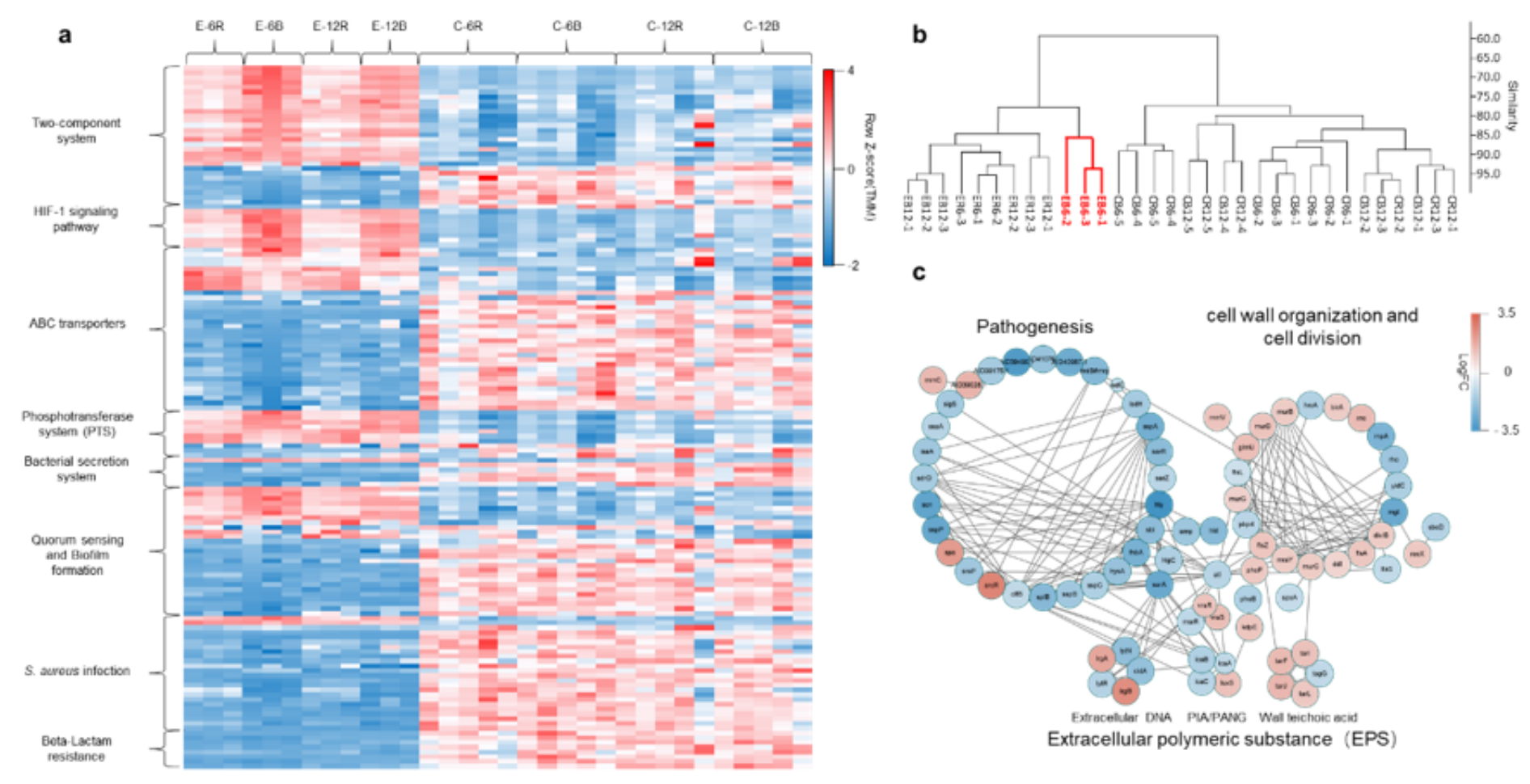

\section{Figure 4}

Gene expression of the $6 \mathrm{~h}$-treated MRSA biofilm cells having the most distinct one among all groups. a Heatmap of the expression level of DEGs for selected KEGG pathways. b Hierarchical clustering of the RNA-seq data using the normalised reads count. c Networks of DEGs of biofilm cells after $6 \mathrm{~h}$ of elasnin treatment and their functional associations. The nodes were the differentially expressed genes between the control and treatment groups after $6 \mathrm{~h}$ of treatment, and the edges were their associations as predicted by STRING. Red colours indicate that the gene expression was upregulated following elasnin treatment, whereas blue colours indicate that the gene expression was downregulated following elasnin treatment. Note size was indirectly proportional to p-value as described in the Material and Method section (e.g., a larger node corresponded with a smaller p-value). 

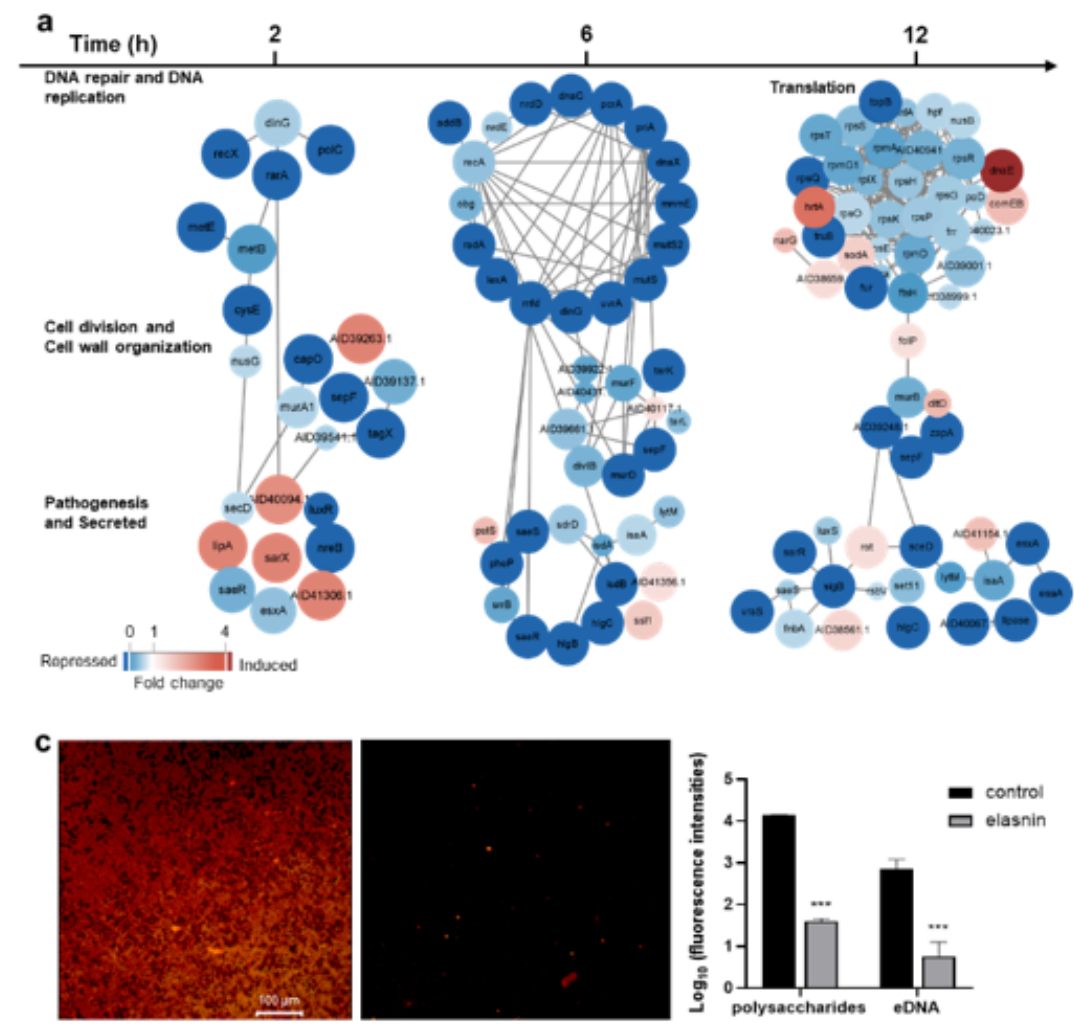
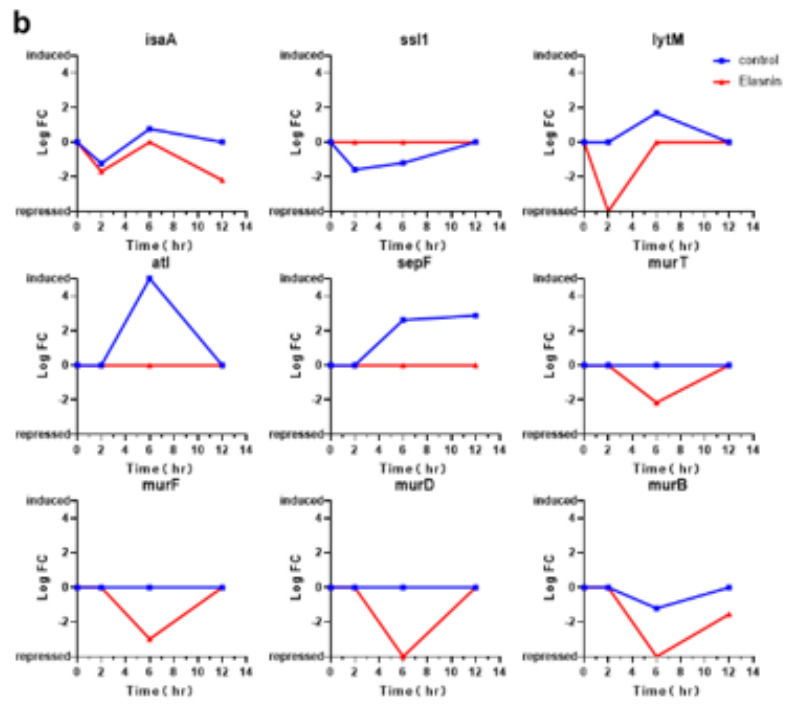

d

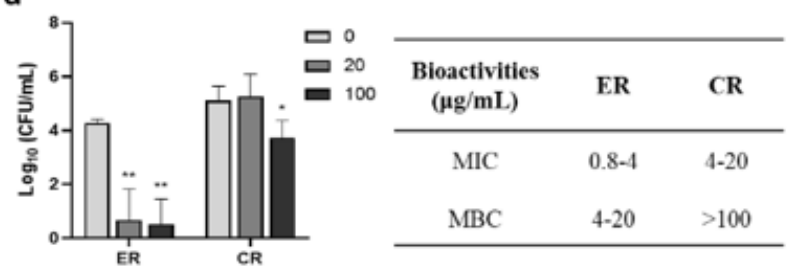

\section{Figure 5}

Elasnin interfered with cell cycle and EPS production and reduced the antibiotic resistance of MRSA. a Differentially expressed proteins (DEPs) in selected functional subsets after 2, 6 and $12 \mathrm{~h}$ of elasnin treatment. $b$ Changes in the expression level of selected DEPs during the biofilm eradication with elasnin. c Effect of elasnin on the production of the EPS components of MRSA biofilm, visualised by confocal microscopy. Fluorescence intensities were calculated based on acquired 3D confocal images $(n=3)$. $d$ Antibiotic susceptibility of MRSA cells against Penicillin $\mathrm{G}$ after they were released from the biofilms $(n=3)$. ER are cells released from the biofilms after elasnin treatment, and CR are cells released naturally (without any treatment). Differences between different groups were calculated by student's t-test and are indicated by asterisks as follows: * for $p<0.05$, ** for $p<0.01$ and $* \star \star$ for $p<0.001$. 


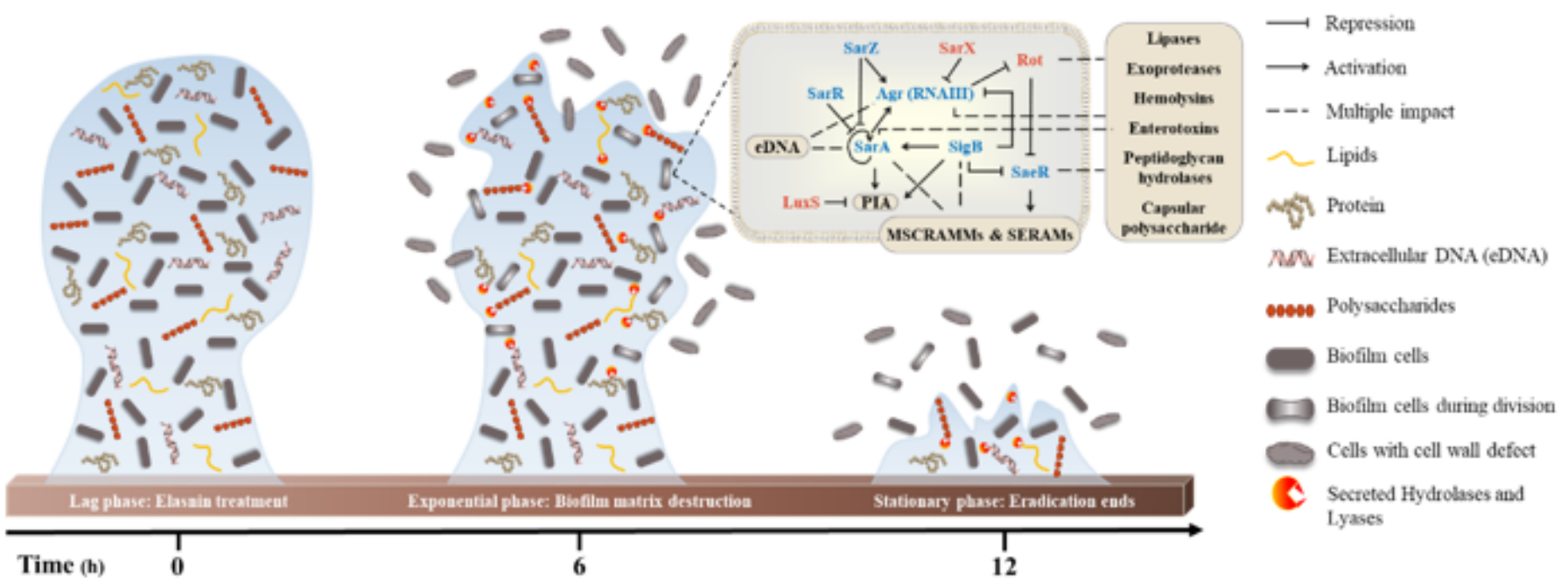

MSCRAMMs: Microbial surface components recognizing adhesive matrix molecules, including clumping factors A and B (CIfA, CIBB), the serine/aspartate-rich protein (Sdr) and fibronectinbinding protein A and B (FnBPA, FaBPB).

SERAMs: Secretable expanded repertoire adhesive molectles, including extracellular adherence protein Eap, extracellular matrix and plasma binding protein Emp (Extracelhular matrix binding protein homologues Ebh is also included in here).

\section{Figure 6}

Proposed model of MRSA-biofilm eradication by elasnin. The peak of eradication occurred in the exponential phase when a large amount of biofilm cells underwent cell division. Elasnin inhibited the expression of virulence factors and interfered with the cell division and EPS production, thereby creating cells with cell-wall defects. At the same time, the increased production of hydrolases and lyases degraded the old EPS, subsequently released the biofilm cells from the biofilms.

a
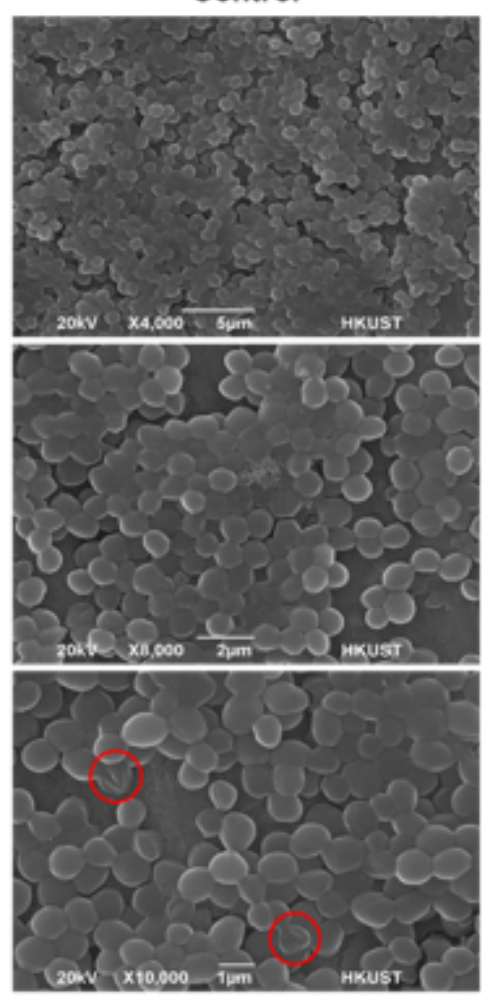

Elasnin
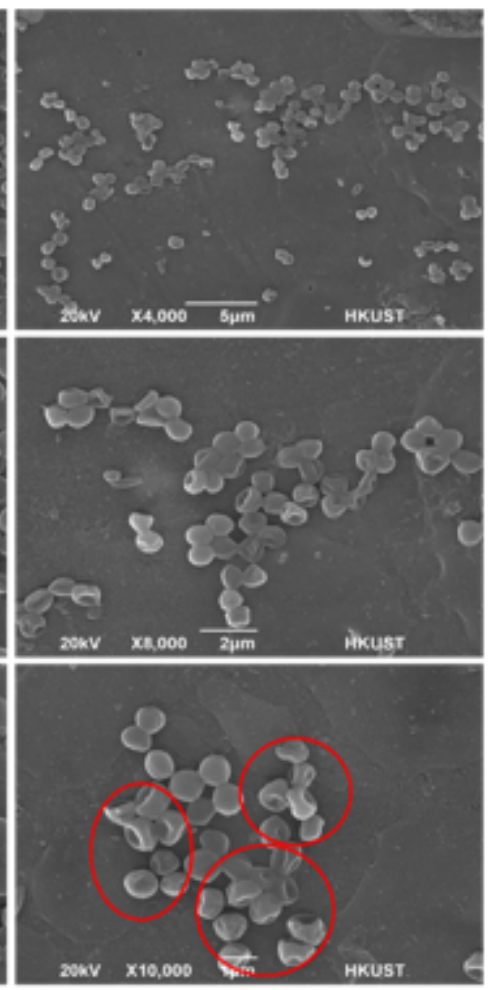

b
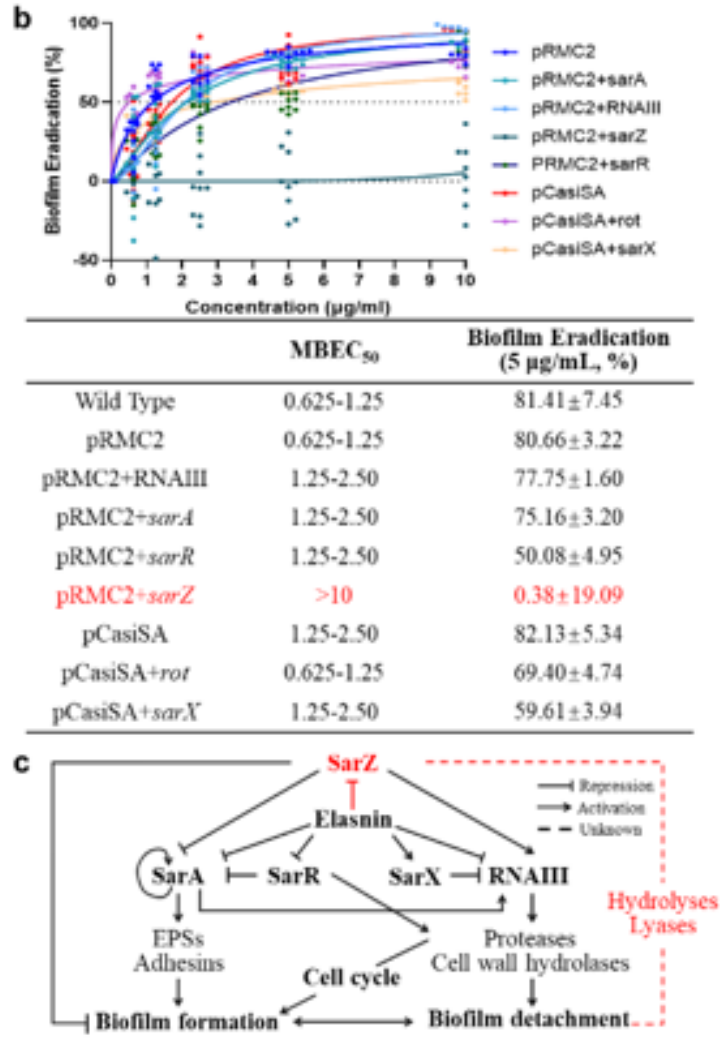


\section{Figure 7}

Validation of the proposed mode of action of elasnin. a Scanning electron microscopy (SEM) of untreated and elasnin-treated biofilm cells. Regions marked with red outlines indicated cells with cell-wall defect. b MBEC and biofilm-eradication efficacy $(5 \mu \mathrm{g} / \mathrm{mL})$ of elasnin against transcription-inhibited and complemented strains $(n=9)$. The expression of complemented genes was induced with $0.2 \mu \mathrm{g} / \mathrm{mL}$ anhydrotetracycline. c Schematic of the regulatory network affected by elasnin during MRSA biofilm formation and biofilm detachment.

\section{Supplementary Files}

This is a list of supplementary files associated with this preprint. Click to download.

- supplimentary.docx 